\title{
Chemical Enhancement of Soil based Footwear Impressions on Fabric
}

Kevin J. Farrugia ${ }^{a b}$, Helen Bandey ${ }^{c}$, Lorna Dawson ${ }^{d}$ and Niamh Nic Daéid ${ }^{a^{*}}$

${ }^{a}$ Centre for Forensic Science, WestCHEM, Department of Pure and Applied Chemistry, University of Strathclyde, Glasgow, G1 1XW, UK

${ }^{\mathrm{b}}$ School of Contemporary Sciences, Division of Forensic and Bio Sciences, University of Abertay, Bell Street, Dundee, DD1 1HG, UK

${ }^{c}$ Centre for Applied Science and Technology (CAST, formerly HOSDB), Home Office Science, Woodcock Hill, Sandridge, St. Albans, AL4 9HQ, UK

${ }^{\mathrm{d}}$ The James Hutton Institute, Macaulay Drive, Craigiebuckler, Aberdeen, AB15 8QH, UK

\section{* CORRESPONDING AUTHOR}

Niamh Nic Daéid

Centre for Forensic Science, WestCHEM, Department of Pure and Applied Chemistry,

University of Strathclyde, Glasgow, G1 1XW, UK

n.nicdaeid@strath.ac.uk 


\section{ABSTRACT}

This study investigates the enhancement of footwear impressions prepared with soils from different locations on a variety of fabric surfaces with different morphology. Preliminary experiments using seventeen techniques were carried out and the best responding reagents were evaluated further.

Results indicated that the soils investigated (a cross section of soils from Scotland) are more likely to respond to reagents that target iron ions rather than calcium, aluminium or phosphorus ions. Furthermore, the concentration of iron and soil $\mathrm{pH}$ did not appear to have an effect on the performance of the enhancement techniques. For the techniques tested, colour enhancement was observed on all light coloured substrates while enhancement on dark coloured fabrics, denim and leatherette was limited due to poor contrast with the background.

Of the chemical enhancement reagents tested, 2,2'-dipyridil was a suitable replacement for the more common enhancement technique using potassium thiocyanate. The main advantages are the use of less toxic and flammable solvents and improved clarity and sharpness of the enhanced impression. The surface morphology of the fabrics did not have a significant effect on the enhancement ability of the reagents apart from a slight tendency for diffusion to occur on less porous fabrics such as polyester and nylon/lycra blends.

Keywords: footwear impressions, soil, fabric morphology, iron, $\mathrm{pH}$, enhancement 


\section{INTRODUCTION}

Recent research has shown the successful visual and fluorescent enhancement of footwear impressions in blood and urine on a variety of fabrics surfaces and colours [1-4], however, in general, research on the recovery and enhancement of impressions on fabric is generally limited [5-12]. Fabrics are regarded as difficult surfaces from which to enhance footwear impressions and this is particularly the case where dark fabrics are encountered. This work seeks to relate the difficulty of the enhancement of footwear impressions made in soil to both the chemistry of the soil involved as well as the morphology of the fabric and the interaction of the soil with the material. Five fabrics (cotton; polyester; nylon/lycra; denim; leatherette) were chosen encompassing a normal range of fabrics encountered operationally. It is hypothesised that the efficiency of enhancement will depend on the type of fabric involved and the nature of the contact trace (in this case soil) interaction.

Fabric fibres can be divided into four groups: fibres occurring in nature, man-made fibres manufactured from either natural or synthetic polymers, synthetic fibres and regenerated fibres [13]. An example of a natural fibre is cotton, which is the purest form of cellulose. Microscopically, cotton fibres can be identified from the extensive twists or convolutions. Synthetic fibres include polyester and nylon. Polyester is derived from the condensation reaction between an acid and an alcohol where the fibres formed lack any microscopic features and have an even diameter with specks of delustring agent. Nylon fibres are formed from the condensation reaction of a diamine and dicarboxylic acid. Similar to polyester, nylon does not have any identifiable microscopic features of note. Kadolph et al.[14] define denim as "a cotton or cotton/polyester blend, twill-weave, yarn dyed fabric where usually the warp is coloured and the filling is white. It is usually a left-hand twill that is commonly available with a blue (indigo) warp and white filling for use in apparel." Denim fabric is extensively used throughout the word due to its fit, ease of use and durability. Leather is manufactured in a three-step process involving preparation, tanning and crusting [15]. Leatherette, or artificial leather, is usually prepared by covering a fabric base with a pyroxylin coated sheeting of various weights and leather-like textures. It does not have the flexibility or same characteristics of genuine leather.

One of the important features of a surface upon which enhancement reagents are used is the porosity of the surface. In the textile industry, air permeability and porosity may be wrongly interchanged. The American Society for Testing and Materials (ASTM) standard D737-04 [16] 
defines air permeability as "the rate of air flow under a differential pressure through a material" whereas standard D4850-08 [17] defines porosity as the "ratio of the volume of air or void contained within the boundaries of a material to the total volume (solid material plus air or void) expressed as a percentage" and there is a known relationship between the air permeability and porosity of some fabrics [18].

Soil is "the collection of natural bodies in the earth's surface, in places modified or even made by man of earthy materials, containing living matter and supporting or capable of supporting plants out-of-doors" [19]. Soils have a wide range of chemical, physical and biological characteristics including mineralogy, elemental concentrations, $\mathrm{pH}$ and organic matter content. Commonly available enhancement techniques for muddy footwear impressions normally target iron or calcium ions [8, 9, 20-26], and it is thus hypothesised that the efficiency of enhancement techniques will differ with the type of soil (and its associated chemical characteristics) and its adherence to the fabric. The presence of iron compounds in soil imparts colour indicating drainage characteristics and weathering conditions of the soil. [27]. Calcium is abundantly present in soils as carbonate, phosphate, silicate, fluoride and sulphate salts, however, it is typically deficient in very acidic soils and sodium-rich alkali soils [27].

\section{Enhancement Techniques reacting with iron}

Someha [25] describes the successful enhancement of footwear impressions in soil using five chemical techniques (potassium thiocyanate, potassium ferrocyanide, phenanthroline hydrosulfite, ammonium pyrrolidinedithiocarbamate and 2,2-dipyridil), targeting the ferric $\left(\mathrm{Fe}^{+3}\right)$ content of soil. All five techniques utilised hydrochloric acid to liberate ferrous $\left(\mathrm{Fe}^{2+}\right)$ and ferric $\left(\mathrm{Fe}^{3+}\right)$ ions in the soil. This research was conducted on soil with a mean average ferric iron content of $10 \%$, reported vibrant coloured enhancement on a variety of substrates from these techniques [25].

Ammonium and potassium thiocyanate have been developed for the enhancement of footwear impressions with successful results [21, 26, 28]. These techniques are commonly used to enhance muddy footwear impressions to improve contrast where any impressions containing ferric iron $\left(\mathrm{Fe}^{3+}\right)$ produce a reddish brown colour. Studies evaluating these two compounds determined that they both work equally well in enhancing dusty footwear prints on plywood and brown paper [28]. Other research has demonstrated that ammonium thiocyanate provided the best results for the enhancement of muddy footwear impressions on vinyl flooring when compared to pyridyldiphenyl-triazine (PDT) and Ferrotrace ${ }^{\circledR}$ (a commercial version of PDT) 
[24]. Some preference has been suggested for ammonium thiocyanate because of its ease of application (mix and spray) over potassium thiocyanate which requires an additional separation of layers [21]. Both working solutions have a shelf life of about five weeks [28]. The reaction of thiocyanate ions with ferric ions is presented in equation 1.

$\left[\mathrm{Fe}\left(\mathrm{H}_{2} \mathrm{O}\right)_{6}\right]^{3+}+\mathrm{SCN}^{-} \rightarrow\left[\mathrm{Fe}(\mathrm{SCN})\left(\mathrm{H}_{2} \mathrm{O}\right)_{5}\right]^{2+}+\mathrm{H}_{2} \mathrm{O}$

[Equation 1]

The reaction of potassium ferrocyanide with $\mathrm{Fe}^{3+}$ produces a dark blue precipitate (Prussian blue) and is presented in equation 2 .

$\mathrm{K}^{+}+\mathrm{Fe}^{3+}+\left[\mathrm{Fe}[\mathrm{CN})_{6}\right]^{4-} \rightarrow \mathrm{KFe}\left[\mathrm{Fe}(\mathrm{CN})_{6}\right]$

[Equation 2]

Potassium ferrocyanide also reacts with $\mathrm{Fe}^{2+}$ to form a white precipitate which is oxidised quickly by air to give a blue colour [29].

Ammonium pyrrolidinedithiocarbamate (APD), also known as ammonium pyrrolidinecarbodithioate $\left(\mathrm{C}_{5} \mathrm{H}_{9} \mathrm{NS}_{2} \cdot \mathrm{NH}_{3}\right.$ ), reacts with $\mathrm{Fe}^{3+}$ (as presented in equation 3 ) to give a black colour which fades quickly, although improved results have been reported on nonporous articles [22].

$3 \mathrm{C}_{5} \mathrm{H}_{9} \mathrm{NS}_{2} \cdot \mathrm{NH}_{3}+\mathrm{Fe}^{3+} \longrightarrow \mathrm{Fe}\left(\mathrm{C}_{5} \mathrm{H}_{9} \mathrm{NS}_{2}\right)_{3}+3 \mathrm{NH}_{3}$

[Equation 3]

2,2'-dipyridil is a bipyridine isomer which can be used for the colourimetric analysis of iron. Ascorbic acid is added to reduce $\mathrm{Fe}^{3+}$ to $\mathrm{Fe}^{2+}$ which reacts with 2,2'-dipyridil producing a red complex. The reaction of $\mathrm{Fe}^{2+}$ with phenanthroline forms a red-orange coloured complex following reduction of $\mathrm{Fe}^{3+}$ to $\mathrm{Fe}^{2+}$ by sodium hydrosulfite [30].

8-hydroxyquinoline reacts with trace amounts of calcium, magnesium, iron, aluminium and other metal ions [31] and has been previously utilised for determining whether a person had handled a weapon [32] as well as for the development of footwear impressions on wood [33].

Tetramethylbenzidine, TMB, has been successfully used as a peroxidase reagent for the enhancement of footwear impressions in blood on porous surfaces [34] and as a presumptive test for blood [35]. It reacts with iron in haemoglobin in a similar way to other peroxidase 
reagents such as leuco crystal violet, leucomalachite green and fluorescein. The same reagent formulation can be applied for the enhancement of muddy footwear impressions [26, 36]. Hemastix $^{\circledR}$ is a commercially available TMB strip test which eliminates the use of dangerous TMB solutions as TMB is believed to be carcinogenic, although to a lesser degree than benzidine and o-tolidine $[37,38]$. Hemastix ${ }^{\circledR}$ was recently classified as a specific test that is easy to transport and apply at crime scenes and does not interfere with subsequent DNA analysis [39].

\section{Enhancement Techniques Reacting with Other Components in Soil}

Bodziak [31] highlights the fact that soil, dust and mud have different compositions in different parts of the world and some techniques might not work in every country. Israel for example has rich calcium carbonate soils. Alizarin red $\mathrm{S}$ can act as a chelating agent for several ions, including calcium forming a red complex [40]. The reagent has been successfully used in Israel for the enhancement of footwear impressions in dust using a saturated solution in ethanol [23].

Glattstein et al [8] investigated bromophenol blue (BPB), a $\mathrm{pH}$ indicator, for its potential to enhance impressions in dust. BPB exhibits a colour change from yellow (at a $\mathrm{pH}$ of about 3.0) to blue (at a $\mathrm{pH}$ of about 4.6) and reacts with trace amounts of calcium carbonate $\left(\mathrm{CaCO}_{3}\right)$, commonly found in dust and soil, providing an immediate colour change from yellow to an intense blue colour. This technique is limited when insufficient carbonates are present in the dust or soil. Further research by Shor et al [9] illustrated that better contrast and enhancement can be achieved by lifting a dusty footwear impression with a white adhesive lifter and subsequent treatment with BPB. In the UK, the effectiveness of BPB was evaluated [41], however no added advantage was noted over visual examination of the impressions for UK soils. Bromocresol green was reported to behave similarly to BPB when reacting with calcium carbonate [8].

Safranin $\mathrm{O}$ or Basic Red $2\left(\mathrm{C}_{20} \mathrm{H}_{19} \mathrm{ClN}_{4}\right)$ is a biological red stain commonly used for histological purposes. This staining method has been successfully used by Velders [42] to enhance wet and muddy footwear impressions on glass, plastic, flooring and other smooth nonabsorbing surfaces. No explanation of the mechanism involved was discussed although it has been suggested that it may target oils and greases [43]. Safranin O has been reported to be successful for the enhancement of muddy footwear impressions on non-porous substrates [26]. 
1,8-diazafluoren-9-one (DFO) has been utilised to enhance wet or muddy footwear impressions on paper [44] and considerable enhancement was achieved when DFO was applied after the impression was lifted and activated with a black gelatine lifter [45]. Velders [45] suggested that the activation was most likely due to the presence and transfer of amino acids from the gelatin layer to stimulate the paper fibres. This phenomenon is explained further by Theeuwen et al [26] where the authors suggest that "the fibres may have been activated by a combination of water present in the mud and mechanical damage caused by grains of sand, both making the structure of the fibres more open and thus enabling amino acids to migrate in [to the paper]" [26].

Physical Developer (PD) was developed for use when techniques such as ninhydrin fail to develop or enhance latent impressions. PD has been suggested as a possible enhancement technique for muddy footwear impressions where the technique performed well on non-porous substrates but poorly on porous substrates $[26,36]$. Until recently, physical developer has been the only technique capable of developing latent impressions on porous surfaces that have been wetted or subjected to high humidity. Oil Red O (ORO), a lysochrome dye used in biology for targeting soluble lipids, has recently been suggested as a cheaper, less complex alternative to PD [46-52].

Phosphorus can be abundantly present in soils [27] and as a consequence, a phosphorus test may result in enhancement of muddy footwear impressions. The detection of phosphorus requires its conversion to the more soluble orthophospate compound by means of a strong acid such as sulphuric acid. One of the most common techniques for the colourimetric detection of phosphorus involves ammonium molybdate and antimonyl tartrate reacting in an acid medium with orthophospate to form an antimony-phospo-molybdate complex which in turn is reduced to an intensely blue-coloured complex by ascorbic acid [53].

Aluminium is another element that can be abundantly present in soils. Pyrocatechol violet (PCV) produces a blue colour when a chelating complex is formed with aluminium [54, 55]. The complex formed is fairly soluble in water and absorbs light at a high wavelength of around 580-585nm [56]. PCV methods are also sensitive to iron and silica interference. 


\section{MATERIALS AND METHODS}

\section{Deposition of the footwear impressions and preparation of the test marks}

Variables introduced during the preparation of test footwear impressions include the pressure of the footwear sole on the receiving surface as the footwear impression is made. In this work the pressure applied to the receiving surface by the soil contaminated footwear was controlled using a rig developed and calibrated specifically for that purpose. The device was calibrated to repeatably deliver a force comparable with the average force used in a stamping action, as determined through trials conducted with live volunteers (3500 Newtons). The same rig has been utilised in other research for the preparation of footwear impressions in blood and urine on fabric [1-4]. Other influencing factors on the quality of the impression include the amount and composition of soil on the footwear sole prior to being transferred to the receiving surface and the actual amount of contaminant transferred to the substrate [57]. Although these variables are challenging to control during experimental trials, the following methodology attempted to limit the effects of such variables.

Muddy footwear impressions were prepared by sifting the soil material through a $4 \mathrm{~mm}$ sieve into a tray (up to a depth of about $3 \mathrm{~cm}$ ) to remove any stones and twigs. Excess water was then added to the tray, mixed and the mixture allowed to settle for about two hours before decanting the excess water. The mixture was then allowed to settle for a further two hours to give a slurry. After stepping into the slurry, a diminishing series of muddy footwear impressions was prepared from $0-10$ (11 impressions) where the $0^{\text {th }}$ impression was the first most loaded impression and the rest of the impressions were prepared without re-loading the shoe with mud. All impressions were allowed to age for 7 days before enhancement with the various reagents. Photography of all impressions was performed immediately after the impression was prepared, after 7 days, after chemical treatment and during fluorescence examination if required.

\section{Blank Tests}

Before the contact between soil and the sole of the footwear, wet and dry negative controls were prepared for each reagent and fabric surface. A dry negative control was performed by stamping on the fabric without any soil on the sole of the footwear, ensuring the sole was dry. A wet negative control involved stepping on a distilled water-soaked tissue before stamping on the fabric. These controls, ensured that the staining observed was not due to additives such as plasticisers in the footwear sole or impurities in the water used. 


\section{Computer Monitor and Colour Calibration}

Computer monitor and colour calibration for the visualisation of the enhanced impressions was achieved as described elsewhere [2].

\section{Fabric Analysis}

Nine different fabrics were examined and are listed in table 1 . The air permeability of each fabric was measured using an air permeometer (model number 4301N) by Gurley Precision Instruments, NY, USA (www.gurley.com). Scanning electron microscope (SEM) analysis of the test fabrics was performed using a Hitachi S-4300 cold field emission SEM both in the presence and absence of soil. This technique required a small sample for measurement (127 $\left.\mathrm{mm}^{2}\right)$.

Table 1 - List of fabrics used in the study

\begin{tabular}{|c|c|}
\hline Fabric & Supplier \\
\hline $\begin{array}{c}\text { White Cotton [CD13] } \\
\text { Plain weave; 19 warp threads/cm; 10 weft } \\
\text { threads/cm }\end{array}$ & WBL Whaleys Bradford Ltd. \\
\hline $\begin{array}{c}\text { Black Cotton [CD13D] } \\
\text { Plain weave; 19 warp threads/cm; 10 weft } \\
\text { threads/cm }\end{array}$ & WBL Whaleys Bradford Ltd. \\
\hline $\begin{array}{c}\text { Patterned Cotton [SF2360/B] } \\
\text { Twill weave; 19 warp threads/cm; 19 weft } \\
\text { threads/cm }\end{array}$ & WBL Whaleys Bradford Ltd. \\
\hline White Polyester Taffeta [SF25] & WBL Whaleys Bradford Ltd. \\
\hline Black Polyester Taffeta [SF25A] & WBL Whaleys Bradford Ltd. \\
\hline $\begin{array}{c}\text { White Nylon (82\%) / Lycra (18\%) [SF28] } \\
\text { Black Nylon (82\%) / Lycra (18\%) [SF27] }\end{array}$ & WBL Whaleys Bradford Ltd. \\
\hline $\begin{array}{c}\text { Blue Denim [Rialto Indigo] } \\
\text { weave; 25 warp threads/cm; 19 weft } \\
\text { threads/cm }\end{array}$ & WBL Whaleys Bradford Ltd. \\
\hline $\begin{array}{c}\text { Plain Dyed Brown Leatherette } \\
\text { KBT (C2708) (68) (F10) }\end{array}$ & Mandors, Glasgow, UK \\
\hline
\end{tabular}




\section{Soil Sampling}

Four soil types were chosen and represent the main different soil types available in Scotland including those containing aluminium and phosphorous $[58,59]$. In addition, the enhancement effect of soil from a busy roadside under the M8 motorway in Glasgow was investigated. The soils collected were chosen using the Scottish Soil Knowledge and Information Base [SSKIB, (http://sifss.macaulay.ac.uk/SSKIB_Stats.php)] and are presented in table 2 and figure 1. These soils included a calcareous soil (North Berwick), an organic soil (Cornalees), and two mineral soils with a high (Kilbirnie) and low (Wemyss Bay) clay content.

Table 2 - Characteristics of the soil samples used in the study

\begin{tabular}{|c|c|c|c|}
\hline Soil Type & Soil Area Location & Soil Grid Position & Soil Description \\
\hline Mineral high clay (30\%) & Kilbirnie & NS 32495, 54282 & Brown/black, lumpy \\
\hline Organic & Cornalees & NS 23473, 70754 & Grey, rocky \\
\hline Calcareous & North Berwick & NT 51591, 85718 & $\begin{array}{c}\text { Dark brown, sandy, } \\
\text { sticky }\end{array}$ \\
\hline Mineral low clay (10\%) & Wemyss Bay & NS 19888, 70600 & Red/light brown \\
\hline
\end{tabular}

Soils were collected from the top 5mm using a sterile trowel and stored in a sterile container before transportation back to the laboratory where samples were air dried, sieved and prepared for the deposition of footwear impressions.

\section{Soil Analysis}

pH Analysis

The $\mathrm{pH}\left(\mathrm{H}_{2} \mathrm{O}\right)$ of each soil sample was obtained by adding deionised water $(45 \mathrm{~mL})$ to the appropriate soil sample $(15 \mathrm{~g})$ before taking a $\mathrm{pH}$ reading using a calibrated $\mathrm{pH}$ meter. $\mathrm{pH}$ $\left(\mathrm{CaCl}_{2}\right)$ was performed by adding $\mathrm{CaCl}_{2}(5 \mathrm{~mL}$ of $0.1 \mathrm{M})$ to the previous slurry prior to taking the $\mathrm{pH}$ reading.

\section{Elemental Analysis}

Elemental analysis was carried out using an Agilent 7500ce inductively coupled plasma - mass spectrometry (ICP-MS) and a Perkin Elmer 5300DV inductively coupled plasma - optical emission spectrometer (ICP-OES). The samples were digested by adding concentrated $\mathrm{HCl}$ $(21 \mathrm{~mL})$ to the appropriate dried soil $(2 \mathrm{~g})$ followed by $\mathrm{HNO}_{3}(7 \mathrm{~mL})$. The samples were then refluxed for 2 hours, filtered through a 541 Whatman filter paper and diluted to $100 \mathrm{~mL}$. 

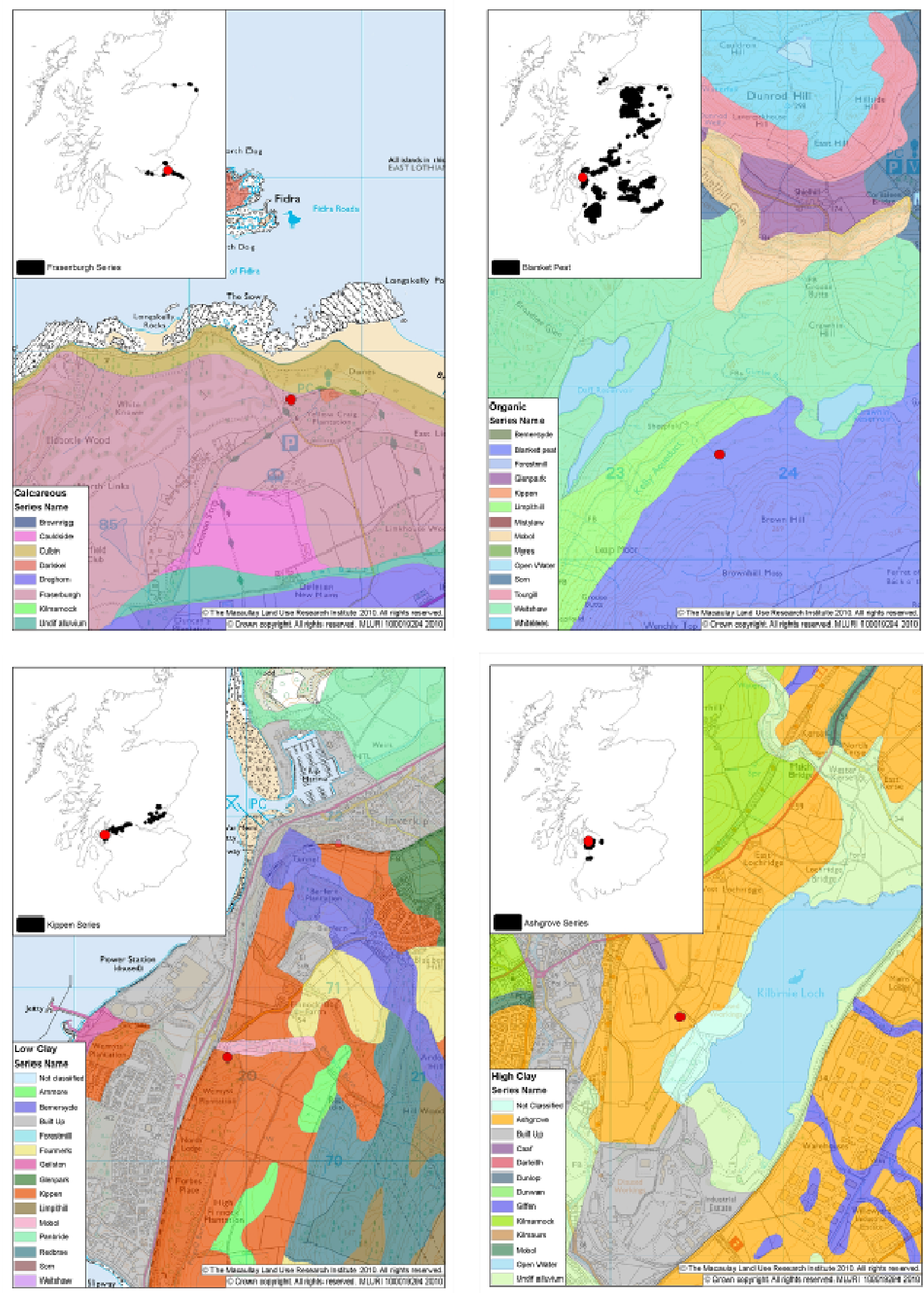

Figure 1 - Location of soils utilised in the study (clockwise from top left: North Berwick, Cornalees, Kilbirnie, and Wemyss Bay). GIS maps provided by Malcolm Coull, The James Hutton Institute. 


\section{Chemical Enhancement Formulations}

The chemical formulations for the enhancement techniques were prepared as follows:

\section{Ammonium Thiocyanate and Potassium Thiocyanate $[21,25,28]$}

Ammonium thiocyanate formulation: ammonium thiocyanate (3g, Acros) was dissolved distilled water $(15 \mathrm{~mL})$. Acetone $(120 \mathrm{~mL}$, Sigma) and concentrated nitric acid (8mL, Riedel-de Haën) were added and the mixture stirred with a magnetic stirrer for a few minutes.

Potassium Thiocyanate formulation: potassium thiocyanate (15g, Sigma) was dissolved in distilled water $(15 \mathrm{~mL})$ and acetone $(120 \mathrm{~mL}$, Sigma) and stirred thoroughly with a magnetic stirrer. Dilute sulphuric acid (8.5mL, Sigma) was added slowly to produce a milky mixture which eventually separated in two layers. The top layer was poured into a dark glass bottle.

Treatment of articles: The reagents were lightly sprayed over the impression using the Ecospray ${ }^{\circledR}$. Controlled spraying was essential to avoid running and bleeding of the original impression. The impressions were then examined for potential fluorescence using a Mason Vactron 40 Quaser and a green excitation filter (band pass filter 473-548nm at 1\% cut-on and cut-off points respectively) and viewed with a long pass $549 \mathrm{~nm}$ filter (1\% cut-on point).

Potassium Ferrocyanide [25]

\section{Reagent formulation:}

Solution A: hydrochloric acid (10mL, Sigma) and ethanol (90mL, Sigma).

Solution B: potassium ferrocyanide (5g, Acros) dissolved in distilled water $(100 \mathrm{~mL})$.

Both solutions had a shelf life of a few months if refrigerated.

Treatment of articles: The articles were sprayed lightly with Solution A using the Ecospray ${ }^{\circledR}$ and allowed to stand for 10-20 seconds. Then, while the sprayed area was still damp, the article was lightly sprayed with solution B ensuring not too spray heavily as this solution contains a large amount of water. 


\section{Reagent formulation:}

Solution A: hydrochloric acid (1mL, Sigma) and ethanol (9mL, Sigma).

Solution B: ammonium pyrrolidinedithiocarbamate (1g, Acros) and sodium citrate (3g, Sigma) were dissolved in ethanol (50mL, Sigma) and distilled water $(50 \mathrm{~mL})$.

Both solutions had a shelf life of about six months if refrigerated, although print clarity reduced with time.

Treatment of articles: The articles were sprayed lightly with solution A using the Ecospray ${ }^{\circledR}$ and allowed to stand until completely dry (about 30 seconds). The articles were then lightly sprayed with solution B. The second process was repeated until satisfactory results were achieved.

\section{2,2’-Dipyridil [25]}

Reagent formulation: 2,2'-bipyridine (4g, Acros) and ascorbic acid (1g, Acros) were dissolved in ethanol (100mL, Sigma) followed by the addition of hydrochloric acid (3mL, Sigma). This solution had a shelf life of about six months if refrigerated.

Treatment of articles: The articles were lightly sprayed with the prepared solution using the Ecospray ${ }^{\circledR}$.

Phenanthroline Hydrosulfite [25]

Reagent formulation: phenanthroline hydrochloride (0.05g, Acros) and sodium hydrosulfite (10g, Sigma) were dissolved in distilled water $(100 \mathrm{~mL})$.

Treatment of articles: The articles were lightly sprayed using the Ecospray ${ }^{\circledR}$.

$\underline{\text { 8-hydroxyquinoline }[20,33]}$

Reagent formulation: 8-hydroxyquinoline $(0.5 \mathrm{~g}$, Acros) was dissolved in acetone $(90 \mathrm{~mL}$, Sigma) and distilled water $(10 \mathrm{~mL})$. 
Treatment of articles: The articles were lightly sprayed with the prepared solution using the Ecospray ${ }^{\circledR}$. The samples were observed visually and using fluorescence examination under UV light $(254 \mathrm{~nm})$. A positive reaction results in fluorescence detectable in the ultraviolet (UV) light range.

\section{Tetramethylbenzidine (TMB) $[26,60]$}

\section{Reagent formulation:}

Solution A: TMB (1g, Acros) dissolved in ethanol (200mL, Sigma).

Solution B: ethanol (90mL, Sigma), distilled water $(90 \mathrm{~mL})$ and $30 \%$ hydrogen peroxide (20mL, Merck).

Treatment of articles: The articles were sprayed lightly using the Ecospray ${ }^{\circledR}$ with solution A followed by solution B.

\section{Alizarin Red S [23]}

Reagent formulation: Alizarin red S was added in excess to ethanol (100mL, Sigma) until saturated.

Treatment of articles: The impressions were lightly sprayed using the Ecospray ${ }^{\circledR}$.

Bromophenol Blue (BB) and Bromocresol Green (BG) [8, 9, 23]

Reagent formulations: BB or BG (1g, Acros) was dissolved in methanol (95mL, Sigma) and distilled water $(5 \mathrm{~mL})$.

Treatment of articles: The articles were lightly sprayed using the Ecospray ${ }^{\circledR}$ to avoid diffusion and background staining as much as possible. If the enhancement was not satisfactory, the impressions were exposed to water vapour from a boiling kettle or steam iron [8]. 


\section{$\underline{\text { Safranin O [42] }}$}

Reagent formulation: Safranin O (1g, Acros) was dissolved in distilled water (1L) and stirred with a magnetic stirrer until all solid was dissolved to give a dark pink solution.

Treatment of articles: A black gelatin lifter was applied to the impression, lifted and photographed. Safranin solution was poured over the original impression and allowed to remain in contact for at least two minutes before rinsing thoroughly under running tap water. Water was allowed to drain from the fabric and left to dry overnight. A white gelatin lifter was then applied to the impression and left for several minutes before checking for potential fluorescence using a Mason Vactron 40 Quaser and a green excitation filter (band pass filter $473-548 \mathrm{~nm}$ at $1 \%$ cut-on and cut-off points respectively) and viewed with a long pass $549 \mathrm{~nm}$ filter (1\% cut-on point). Development of a red fluorescent colour denotes a positive reaction.

\section{1,8-Diazafluoren-9-one (DFO) [44]}

Reagent formulation: Two methods using DFO were employed for the enhancement of muddy footwear impressions.

\section{Method 1}

DFO Formulation: DFO (0.25g, BVDA) was dissolved in methanol (30mL, Sigma) using a magnetic stirrer to produce a slurry. Acetic acid $(20 \mathrm{~mL}$, Sigma) was added and stirred until a clear, yellow solution was produced followed by the addition of HFE71DE $(275 \mathrm{~mL}, 3 \mathrm{M}$ Novec) and HFE7100 (725mL, 3M Novec).

Treatment of articles: The articles were immersed in the working solution for a maximum of five seconds. The excess solution was allowed to drain back into the tray. The fabric was allowed to dry completely before being heated in an oven at $100^{\circ} \mathrm{C}$ for 20 minutes without humidification. Fluorescence examination was carried out using a green excitation source (band pass filter $473-548 \mathrm{~nm}$ at $1 \%$ cut-on and cut-off points respectively) and viewed with a band-pass $549 \mathrm{~nm}$ filter (1\% cut-on point). 


\section{Method 2}

A black gelatin lifter was applied to the muddy footwear impression and removed immediately before treatment of the articles as for Method 1.

\section{Physical Developer [44]}

\section{Reagent formulation:}

Maleic Acid Solution: maleic acid (25g, Sigma) was dissolved in distilled water (1L).

Silver Nitrate Solution: silver nitrate (10g, Acros) was dissolved in distilled water $(50 \mathrm{~mL})$.

Working Solution: iron (III) nitrate (30g, Acros), ammonium iron (II) sulphate (80g, Acros) and citric acid (20g, BDH) were added and dissolved in the order given, in distilled water (900mL). The mixture was stirred until completely dissolved and for a further five minutes. Stock detergent solution (40mL, supplied by CAST) was added and stirred for two minutes followed by the addition of the silver nitrate solution $(50 \mathrm{~mL})$ and stirring for a further two minutes.

Treatment of articles: The article was immersed using unserrated forceps in the maleic acid solution for ten minutes. This was followed by immersion in the working solution with gentle rocking for 20 minutes. The article was then washed three times for five minutes in three different dishes each containing distilled which was changed frequently.

\section{Oil Red O (ORO) [46, 48$]$}

\section{Reagent formulation:}

Stain Solution: ORO (1.54g, Acros) was dissolved in methanol (770mL, Sigma). NaOH (9.2g, Sigma) was dissolved in distilled water $(230 \mathrm{~mL})$ and added to the ORO solution. The solution was then stirred and filtered to remove any undissolved solids.

Buffer Solution pH 7: $\mathrm{Na}_{2} \mathrm{CaO}_{3}$ (26.5g, Sigma) was dissolved in distilled water (2L). $70 \%$ concentrate nitric acid (18.3mL, Riedel-de Haën) was added slowly followed by more distilled water to make a total volume of $2.5 \mathrm{~L}$.

Treatment of articles: The articles to be examined were immersed in the stain solution and rocked gently for a period of 60 to 90 minutes. The articles were then immersed in the buffer solution for a few seconds to adjust the $\mathrm{pH}$ and rinsed in distilled water and dried. 


\section{Phosphorus Test (Ascorbic Acid Method) [53]}

\section{Reagent formulation:}

Sulfuric acid, $\mathrm{H}_{2} \mathrm{SO}_{4}, 5 \mathrm{~N}$ : concentrated $\mathrm{H}_{2} \mathrm{SO}_{4}$ (70mL, Sigma) was added to distilled water $(500 \mathrm{~mL})$.

Potassium antimonyl tartrate solution: $\mathrm{K}(\mathrm{SbO}) \mathrm{C}_{4} \mathrm{H}_{4} \mathrm{O}_{6} \cdot{ }^{1}{ }_{2} \mathrm{H}_{2} \mathrm{O}(1.37 \mathrm{~g}$, Acros) was dissolved in distilled water $(400 \mathrm{~mL})$ in a $500-\mathrm{mL}$ volumetric flask, diluted to a final volume of $500 \mathrm{~mL}$ and stored in a glass-stoppered bottle.

Ammonium molybdate solution: $\left(\mathrm{NH}_{4}\right)_{6} \mathrm{Mo}_{7} \mathrm{O}_{24} \cdot 4 \mathrm{H}_{2} \mathrm{O}$ (20g, Acros) was dissolved in distilled water $(500 \mathrm{~mL})$ and stored in a glass-stoppered bottle.

Ascorbic acid, 0.1M: ascorbic acid (1.76g, Acros) was dissolved in distilled water (100mL). The solutions were stable for about one week at $4^{\circ} \mathrm{C}$.

Working solution: the above reagents were mixed in the following proportions for $100 \mathrm{~mL}$ of reagent: $5 \mathrm{~N}_{2} \mathrm{H}_{2} \mathrm{SO}_{4}(50 \mathrm{~mL})$, potassium antimonyl tartrate solution $(5 \mathrm{~mL})$, ammonium molybdate solution $(15 \mathrm{~mL})$ and ascorbic acid solution $(30 \mathrm{~mL})$. The mixing of solutions was ensured after the addition of each reagent. The reagent is stable for four hours.

Treatment of articles: The impressions were lightly sprayed using the Ecospray ${ }^{\circledR}$.

\section{Aluminium Test [61]}

\section{Reagent formulation:}

Hexamine Buffer: $15 \%$ hexamine buffer was prepared by dissolving hexamine (75g, Acros) in deionised water $(400 \mathrm{~mL}) .28 \%$ ammonia solution $(16 \mathrm{~mL}, \mathrm{BDH})$ was added and the $\mathrm{pH}$ adjusted to the required value ( $\mathrm{pH} 6.6$ or 9.2) by the slow addition of $5 \mathrm{M} \mathrm{HC1}$ (drops, Sigma).

Pyrocathechol Violet (PCV): The reagent was prepared by dissolving PCV (110mg) in deionised water $(100 \mathrm{~mL})$. The solution was stable for three months.

Treatment of articles: The impressions were lightly sprayed using the Ecospray ${ }^{\circledR}$. 


\section{Preliminary Chemical Enhancement}

17 enhancement techniques, shown in table 3, were evaluated in the initial preliminary phase of the study for their potential enhancement abilities. These techniques were first tested on impressions prepared from a mixture of soil (100g from each of the four selected soils) from different locations on white cotton and nylon/lycra. These two fabrics were chosen for practicality, cost and to observe differences between natural and synthetic fabrics. Preliminary experiments demonstrated that spraying with a very fine atomiser was necessary to avoid diffusion and bleeding of the original muddy impression. Best results were obtained by using an Ecosprayer supplied by Bluestar ${ }^{\circledR}$. This application method was used for all techniques that required spraying.

\section{Detailed Examinations}

The best performing enhancement techniques for muddy footwear impressions on fabric were investigated further for their ability to enhance a diminished series of impressions using each of the fabric types.

\section{Sequencing of Enhancement Techniques}

Four representative fabrics (white cotton, white polyester, black polyester and leatherette) were selected as substrates and marks made using the road dust sample were enhanced using randomised sequences of potassium thiocyanate (1), potassium ferrocyanide (2), APD (3) and 2,2'-dipyridil (4) as the best performing enhancement reagents across all samples and the results evaluated. The sequences are illustrated in table 4.

Table 3 - Enhancement techniques evaluated during the study

\begin{tabular}{|c|c|}
\hline Reaction with metal ions & Reaction with other components \\
\hline Ammonium Thiocyanate & Alizarin Red S (CI 58005) \\
\hline Potassium Thiocyanate & Bromophenol Blue \\
\hline Potassium Ferrocyanide & Bromocresol Green \\
\hline Ammonium pyrrolidinedithiocarbamate & DFO / DFO and gelatin lifting \\
\hline 2,2'-Dipyridil & Physical Developer \\
\hline Phenanthroline Hydrosulfite & Oil Red O \\
\hline 8-hydroxyquinoline & Phosphorus Test (Ascorbic Acid Method) \\
\hline Tetramethylbenzidine & \\
\hline Aluminium Test &
\end{tabular}


Table 4 - Sequential Enhancement

\begin{tabular}{|c|c|}
\hline Sequence Letter & Technique Sequence \\
\hline A & $1,2,3,4$ \\
\hline B & $4,3,2,1$ \\
\hline C & $3,1,4,2$ \\
\hline D & $2,4,1,3$ \\
\hline
\end{tabular}

potassium thiocyanate (1), potassium ferrocyanide (2), ammonium pyrrolidinedithiocarbamate (3) and 2,2'dipyridil (4)

\section{RESULTS AND DISCUSSION}

\section{Soil sampling and analysis}

Except for the road soil sample, all soils appear to have a neutral $\mathrm{pH}\left(\mathrm{H}_{2} \mathrm{O}\right)$ with an average $\mathrm{pH}$ of 7.16 as presented in table 5 .

Table 5 - Soil Analysis

\begin{tabular}{|c|c|c|c|c|c|}
\hline Location & Grid Position & $\begin{array}{c}\mathbf{p H} \\
\left(\mathbf{H}_{2} \mathbf{O}\right)\end{array}$ & $\underset{\left(\mathrm{CaCl}_{2}\right)}{\mathbf{p H}}$ & $\begin{array}{l}\text { \% Weight } \\
\text { Loss on } \\
\text { Ignition }\end{array}$ & $\begin{array}{l}\text { \% Weight } \\
\text { Loss on } \\
\text { Ignition }\end{array}$ \\
\hline & & & & @ 450 $0^{\circ} \mathrm{C}$ & $@ 900^{\circ} \mathrm{C}$ \\
\hline Kilbirnie & $\begin{array}{c}\text { NS } 32495 \\
54282\end{array}$ & 7.05 & 6.80 & 8.21 & 10.14 \\
\hline Cornalees & $\begin{array}{c}\text { NS } 23473 \\
70754 \\
\end{array}$ & 6.59 & 6.40 & 17.57 & 21.77 \\
\hline $\begin{array}{c}\text { North } \\
\text { Berwick }\end{array}$ & $\begin{array}{c}\text { NT } 51591 \\
85718\end{array}$ & 7.75 & 7.57 & 0.82 & 10.10 \\
\hline Wemyss Bay & $\begin{array}{c}\text { NS } 19888 \\
70600\end{array}$ & 7.26 & 7.10 & 3.65 & 5.00 \\
\hline $\begin{array}{c}\text { Road soil } \\
\text { sample }\end{array}$ & $\begin{array}{c}\text { NS } 58404 \\
66408\end{array}$ & 4.82 & 4.16 & 4.21 & 5.36 \\
\hline
\end{tabular}

These values are relatively high in comparison to a mean $\mathrm{pH}$ of 3.45 for Scottish mineral soils, suggesting most soils had been relatively intensively managed with the addition of lime [62]. Liming of soils is the application of basic chemicals to neutralise acidity and increase bacteria activity. The North Berwick soil has the highest $\mathrm{pH}$, due to its calcareous nature whereas the road soil sample appears to be slightly acidic ( $\mathrm{pH}$ of 4.82), although it is still well within the 
frequency distribution for Scottish soils [62]. This is most likely due to the location of the soil as there is consistent vehicle traffic and consequent release of hydrocarbons and carbon dioxide, and no liming would have taken place. The acidic $\mathrm{pH}$ of the roadside soil might have an impact on the enhancement reagent when compared to the other soils. The results of the elemental analysis, presented in table 6, illustrate that the North Berwick soil has the lowest levels of iron present when compared to the other soils. This might also have an impact on the enhancement capability of the techniques.

Table 6 - Elemental Analysis of soils highlighting the abundance of the target elements (Fe, Al, P and Ca)

\begin{tabular}{|c|c|c|c|c|c|}
\hline Element & $\begin{array}{c}\text { Road soil Glasgow } \\
\text { NS58404 } \\
66408\end{array}$ & $\begin{array}{c}\text { Kilbirnie } \\
\text { NS32495, } \\
54282\end{array}$ & $\begin{array}{c}\text { Cornalees } \\
\text { NS23473, } \\
70754\end{array}$ & $\begin{array}{c}\text { North Berwick } \\
\text { NT51591, } \\
85718\end{array}$ & $\begin{array}{c}\text { Wemyss Bay } \\
\text { NS19888, } \\
70600\end{array}$ \\
\hline & \multicolumn{5}{|c|}{ Abundance (mg/kg of sample) } \\
\hline $\mathrm{Ag}$ & 0.23 & 0.26 & 0.11 & 0.03 & 0.05 \\
\hline As & 6.00 & 7.13 & 4.09 & 5.30 & 2.58 \\
\hline $\mathrm{Ba}$ & 225.92 & 210.55 & 127.48 & 21.68 & 32.98 \\
\hline $\mathrm{Cd}$ & 0.94 & 0.85 & 0.09 & 0.12 & 0.04 \\
\hline $\mathrm{Co}$ & 13.04 & 22.41 & 15.95 & 2.49 & 3.96 \\
\hline $\mathrm{Cr}$ & 99.25 & 223.90 & 68.63 & 106.01 & 98.70 \\
\hline $\mathrm{Cu}$ & 183.55 & 125.38 & 250.52 & 4.59 & 7.37 \\
\hline $\mathrm{Hg}$ & 0.18 & 0.19 & $<0.15$ & $<0.15$ & $<0.15$ \\
\hline Mo & 8.96 & 5.98 & 0.31 & 3.39 & 2.95 \\
\hline $\mathrm{Ni}$ & 38.44 & 64.11 & 43.31 & 10.25 & 9.47 \\
\hline $\mathrm{Pb}$ & 164.15 & 151.97 & 14.74 & 16.67 & 19.55 \\
\hline $\mathrm{Pt}$ & 0.05 & $<0.01$ & $<0.01$ & $<0.01$ & 0.02 \\
\hline $\mathrm{Se}$ & 0.75 & 1.16 & 0.30 & 0.23 & 0.52 \\
\hline $\mathrm{Sr}$ & 60.36 & 93.14 & 122.32 & 83.31 & 3.69 \\
\hline $\mathrm{Zn}$ & 730.05 & 367.29 & 102.33 & 37.00 & 31.34 \\
\hline $\mathrm{Al}$ & 13030.00 & 27830.00 & 55750.00 & 2694.09 & 11930.00 \\
\hline $\mathrm{B}$ & 59.65 & 67.27 & 137.32 & 15.62 & 29.02 \\
\hline $\mathrm{Ca}$ & 13400.00 & 10660.00 & 30680.00 & 14450.00 & 222.90 \\
\hline $\mathrm{Fe}$ & 35740.00 & 41300.00 & 31110.00 & 7470.17 & 21320.00 \\
\hline $\mathrm{K}$ & 1372.94 & 2080.67 & 20290.00 & 510.43 & 1403.31 \\
\hline $\mathrm{Mg}$ & 7149.38 & 4698.44 & 35280.00 & 1907.81 & 2608.52 \\
\hline $\mathrm{Mn}$ & 597.54 & 1124.94 & 437.36 & 178.40 & 172.64 \\
\hline $\mathrm{Na}$ & 1046.96 & 470.41 & 555.46 & 307.87 & 96.17 \\
\hline $\mathbf{P}$ & 1262.60 & 2233.31 & 540.00 & 414.63 & 154.34 \\
\hline$S$ & 1071.15 & 1009.54 & 131.60 & 326.95 & 180.50 \\
\hline $\mathrm{Ti}$ & 1779.03 & 1689.99 & 575.56 & 204.12 & 638.65 \\
\hline
\end{tabular}




\section{Interaction of the Soils with Fabrics}

The air permeability of each test fabric was measured, as illustrated in table 7 , by determining the cubic feet of air per square foot of fabric per minute (CFM) which penetrated the given fabric. The CFM measurements were converted into the corresponding SI units (litres per square metre per minute - LSM).

Table 7 - Permeability data of fabrics

\begin{tabular}{|c|c|c|}
\hline Fabric & Permeability (CFM) & Permeability (LSM) \\
\hline White Cotton & 14.9 & 4540.0 \\
\hline Black Cotton & 12.3 & 3747.8 \\
\hline Patterned Cotton & 19.8 & 6033.1 \\
\hline White Polyester & 88.8 & 27057.4 \\
\hline Black Polyester & 60.3 & 18373.4 \\
\hline White Nylon/Lycra & 162.4 & 49483.3 \\
\hline Black Nylon/Lycra & 178.2 & 54297.5 \\
\hline Denim & 9.6 & 2925.1 \\
\hline Leatherette & 0.7 & 213.3 \\
\hline
\end{tabular}

Lower values for air permeability exhibited by denim and leatherette indicate that these fabrics have tight pores and thus less air can penetrate through the material. By contrast, synthetic fabrics had higher values of air permeability suggesting larger voids between the pores of the fabric weave. Additionally, factors such as the different types and sizes of fibres and the weave of the fabric may contribute to the different interactions observed and hence may affect subsequent enhancement.

The soil recovered from North Berwick was retained least by all fabrics, presumably due to the fine nature of the soil. All other soils had a similar retention on the various fabrics studied. Nylon/lycra appeared to retain the soils better than the other fabrics whereas leatherette appeared to be the worst fabric at retaining the soils. This reflects the permeability data of fabrics and suggests that the higher the permeability, the higher the retention of the soil. Smaller soil particles appeared to penetrate into the weave of the fabric for cotton and denim, 
whereas larger soil particles were observed on the surface of the fabric. Similar phenomena were observed for the synthetic fabrics polyester and nylon/lycra, however for polyester most of the particles penetrated into the fabric. Examples of the soil interaction on a cross section of some of the fabrics used are illustrated using SEM in figure 2.

\section{Preliminary enhancement of footwear impressions in mud}

No significant enhancement was achieved or in some cases, deterioration of the original impression was observed using DFO, safranin $\mathrm{O}$, bromophenol blue, bromocresol green, 8hydroxyquinoline, TMB, physical developer, ORO and alizarin red S. Previous research [26] suggested that black gelatin lifting followed by photography was a useful enhancement technique for both porous and non-porous substrates, however, gel lifting may increase the background staining from subsequent chemical enhancement and thus decrease the contrast between the impression and the substrate. In this study, black (before chemical enhancement) and white (after chemical enhancement) gelatin lifting (BVDA) was attempted in the preliminary experiments. In general, although the impression was lifted before chemical enhancement, no further enhancement was achieved and the original impressions appeared to remain intact. Furthermore, no increase in background staining was observed after attempted gelatin lifting. White gel lifting was unsuccessful after chemical treatment of the fabrics used in this study, however, it did not appear to alter the original impression or effect subsequent chemical enhancement.

Techniques used for the detection of phosphorus and aluminium provided limited or no visual or fluorescent enhancement despite the presence of high abundances of these elements as evidenced in table 6 . The phosphorus test resulted in heavy blue background staining obliterating the original footwear impression. The aluminium test provided less background staining but only a slight blue enhancement was achieved without improving on the unenhanced visual image. 

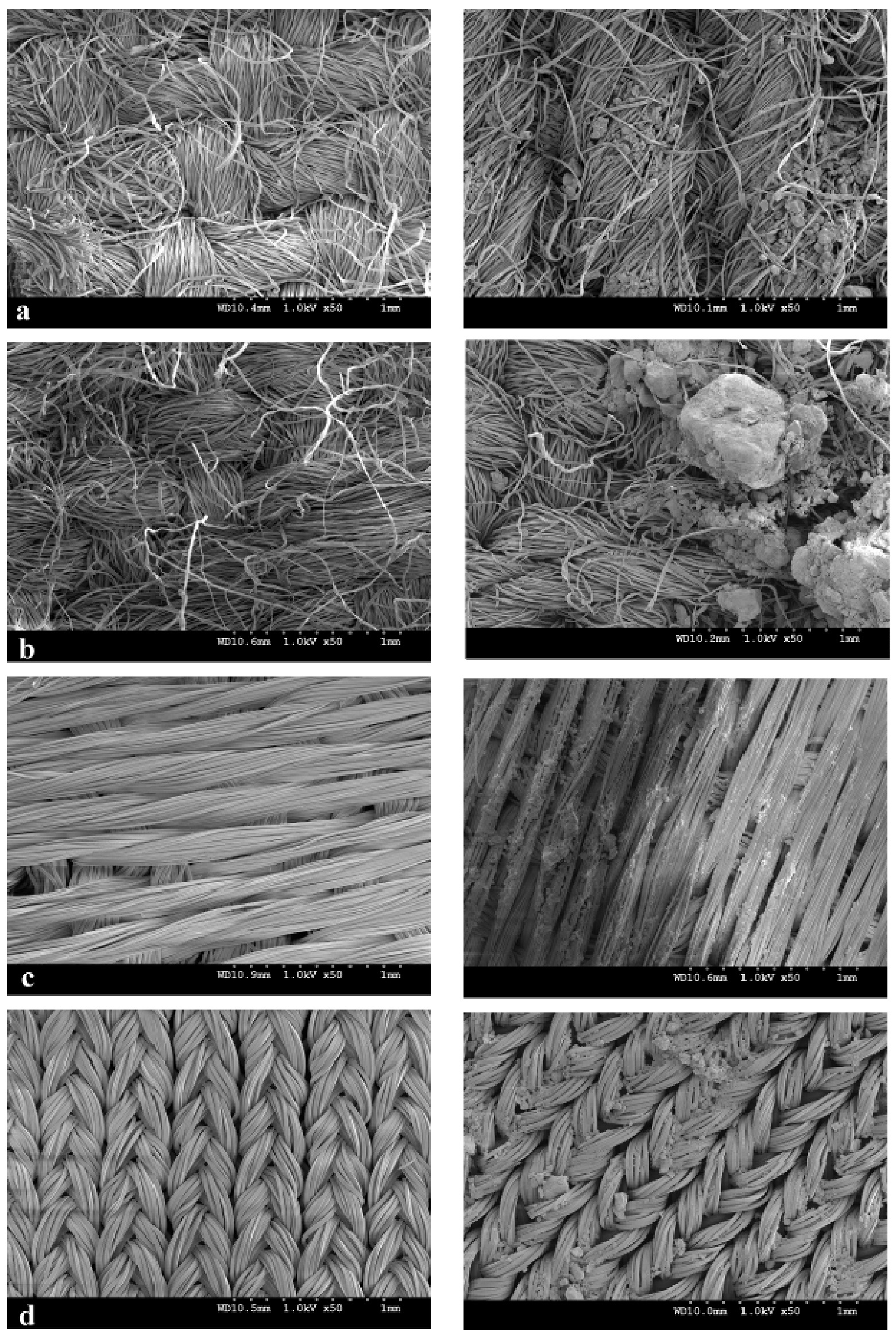

Figure 2 - SEM analysis of fabrics before (left) and after (right) the deposition of mud: (a) white cotton; (b) patterned cotton; (c) black polyester; (d) black nylon/lycra 


\section{Enhancement of footwear impressions on fabric}

Following preliminary experiments, potassium thiocyanate, ammonium thiocyanate, potassium ferrocyanide, ammonium pyrrolidinedithiocarbamate, 2,2'-dipyridil and phenanthroline hydrosulfite were investigated in more detail on all fabrics and using all four soils. Five out of these six enhancement techniques were also recommended by Someha [25] for the enhancement of footwear impressions in mud and dust in Japan and each of these techniques tested target iron ions in the soil. The iron concentration was high to moderate in all soils examined with mean values of $3.58 \%, 4.13 \%, 3.11 \%, 0.75 \%$ and $2.13 \%$ for the roadside, Kilbirnie, Cornalees, North Berwick and Wemyss Bay soils respectively. The mean value for iron ions in Scottish mineral soils is $2.5 \%$, with most soils having values lower than $4 \%$. For organic soils the mean is $0.97 \%$, with most organic soils having values < $1 \%$ [62].

In general, all six techniques provided suitable enhancement for all soils on white fabrics but enhancement was poor on dark and patterned fabrics and leatherette. Lighter spraying on the synthetic fabrics (polyester and nylon/lycra) was essential to avoid diffusion of the original footwear impression. 2,2'-dipyridil was the only technique to offer some enhancement on the black fabrics by improving the contrast with the background, at least in the first impressions of the diminishing series. Weak colour enhancement with all the techniques was observed on footwear impressions prepared using the North Berwick soil. This soil was calcareous and the elemental analysis revealed that the amount of iron present in this soil was considerably less in comparison to the other soils. Furthermore, once the muddy footwear impression prepared with this soil dried on the fabric, extra care was needed as the fine soil became loose and was easily dislodged.

Enhancement on dark coloured fabrics was generally poor with only impressions on black polyester being enhanced to any degree. Some enhancement on black polyester was achieved using oblique lighting (Crime Lite ${ }^{\circledR} 82 \mathrm{~L}$ ) prior to chemical enhancement highlighting the importance of using different lighting conditions and photography. However, the same effect was not observed on any other black or dark fabrics. Figure 3 illustrates the enhancement obtained by oblique lighting on black polyester before and after enhancement. Poor, if any, enhancement was observed on deposited marks on denim or leatherette. 

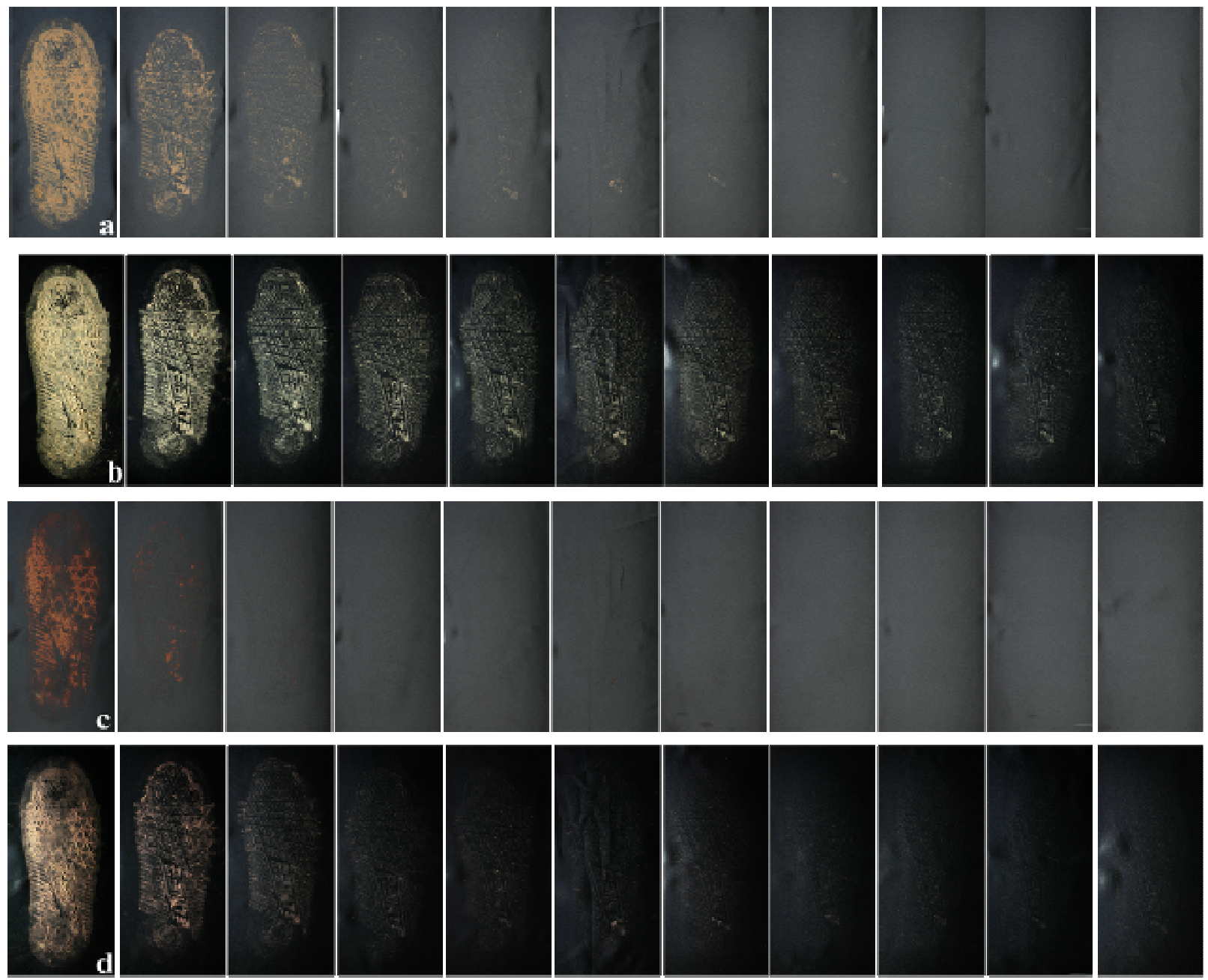

Figure 3 - Chemical enhancement of a diminishing series of footwear impressions in mud, prepared with Wemyss Bay soil on black polyester, with potassium thiocyanate: (a) 1 week old diminishing series; (b) observation with oblique lighting only; (c)) enhancement with potassium thiocyanate; (d) enhanced diminishing series observed with oblique lighting

The Wemyss Bay sample appeared to be the most responsive soil to the chemical enhancement techniques although this soil did not have the highest abundance of iron present (table 6). The North Berwick soil performed poorly across all fabrics and techniques, presumably due to the calcareous nature of the soil and the low abundance of iron.

\section{Ammonium Thiocyanate}

A vibrant red colour enhancement was observed for all footwear impressions in mud on both white and patterned fabrics prepared from all the soils with the exception of the North Berwick sample. The red colour change was not instantaneous and appeared after approximately 10 seconds. The enhancement on dark fabrics provided poor contrast, and in some instances the actual enhancement decreased the contrast of the impression with the background. This adverse 
effect became more pronounced down the diminishing series. The red coloured enhancement faded considerably overnight on all fabrics for all soils, except for impressions on white nylon/lycra. Re-application of the chemical permitted re-visualisation of the footwear impression without detriment to the impression. Limited colour enhancement was observed on denim and leatherette. Figure 4 illustrates exemplars of the results obtained, in this case using Cornalees soil on white cotton.

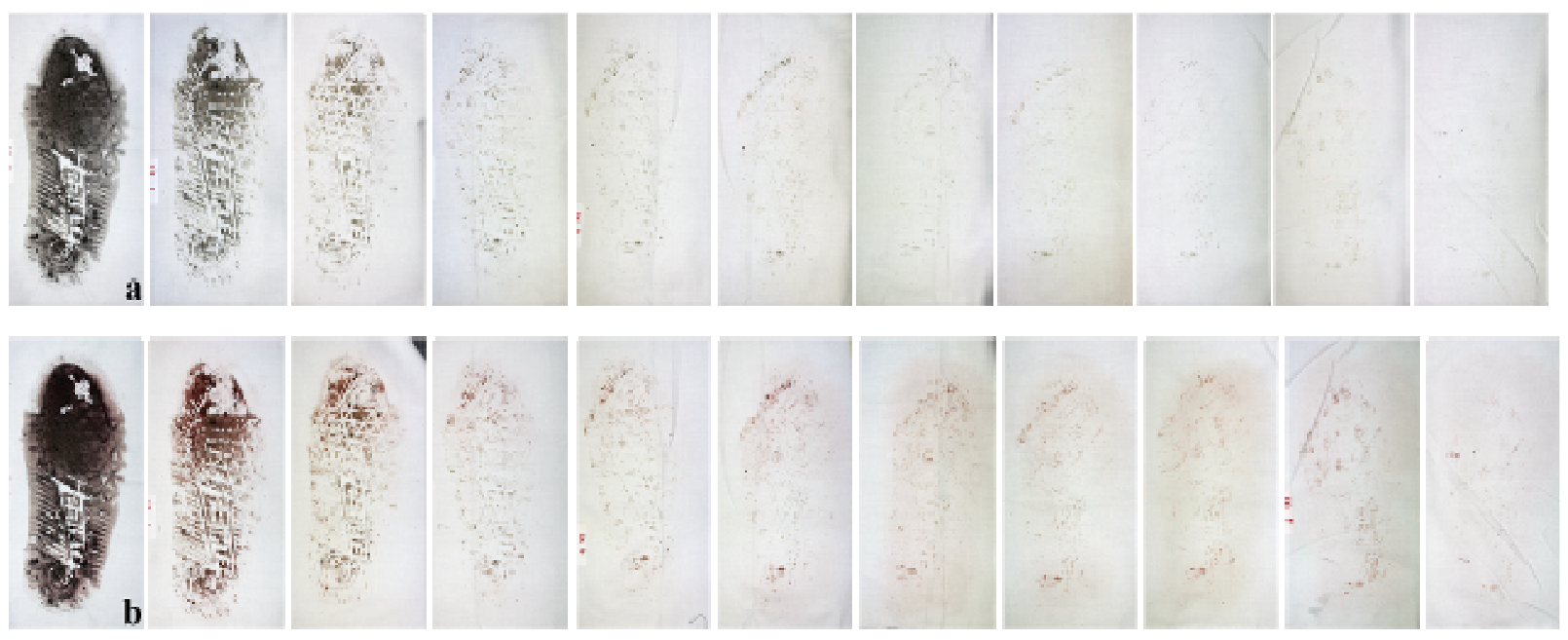

Figure 4 - Chemical enhancement of a diminishing series of footwear impressions in mud, prepared with Cornalees soil on white cotton, with ammonium thiocyanate: (a) before; and (b) after enhancement

\section{Potassium Thiocyanate}

Ammonium and potassium thiocyanate were found to work equally well for the enhancement of muddy footwear impressions and this was corroborated by previous studies [28]. However, it was noted that potassium thiocyanate produced a brighter red colour which developed faster (within 5 seconds) and took longer to fade. Similar to ammonium thiocyanate, the contrast between the impression and the background on black fabrics was poor. Figure 5 illustrates the types of results obtained, in this case using Kilbirnie soil on nylon/lycra. Both thiocyanate techniques emit unpleasant, toxic fumes and use a highly flammable, irritant solvent. 

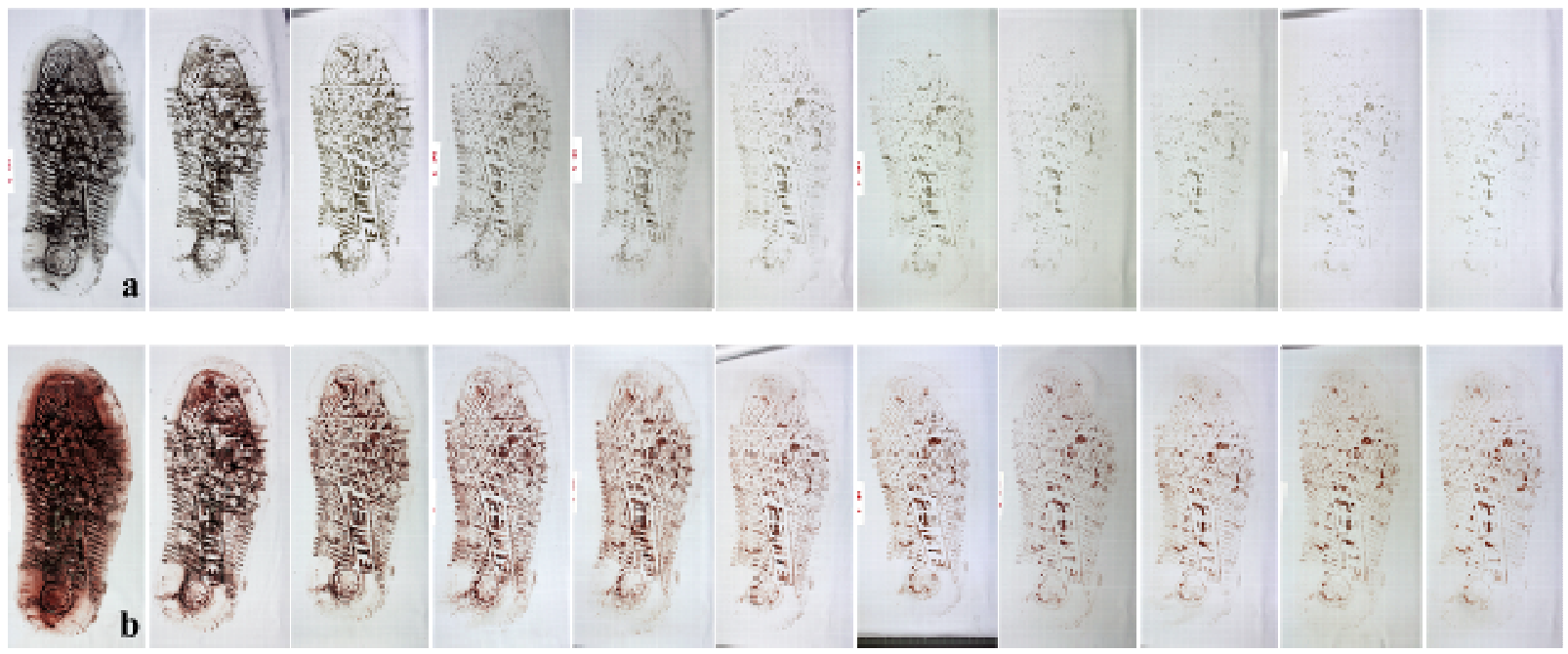

Figure 5 - Chemical enhancement of a diminishing series of footwear impressions in mud, prepared with Kilbirnie soil on white nylon/lycra, with potassium thiocyanate: (a) before; and (b) after enhancement

\section{Potassium Ferrocyanide}

The inclusion of water in the formulation of potassium ferrocyanide increased the potential for diffusion of the impression. The vibrancy and sharpness of this enhancement technique (which produced a blue colour) appeared inferior to that obtained with the thiocyanate reagents with the advantage of using less toxic reagents. However, this technique required the use of two sprayers rather than one, making it slightly more cumbersome. The enhancement appeared more responsive to footwear impressions on the synthetic fabrics (polyester and nylon/lycra) and offered better enhancement on these fabrics than the thiocyanates. The colour enhancement developed a few seconds after spraying, and appeared stronger 24 hours post application. On dark fabrics the contrast between the blue colour and the background was difficult to observe and the enhancement did not greatly improve what could be observed prior to reagent application. Very limited enhancement was obtained with the North Berwick soil across all fabrics, including the light fabrics. Figure 6 illustrates the results obtained for enhancement of impressions made on patterned cotton using the Kilbernie soil.

\section{Ammonium pyrrolidinedithiocarbamate (APD)}

APD produces a black colour and as a result, the enhancement on dark fabrics was not feasible. The technique worked well on light coloured fabrics producing excellent results across the diminishing series. Slight diffusion was observed on polyester, possibly due to the presence of distilled water in the formulation. The enhancement appeared to improve when observed the 
next day. In comparison to the thiocyanates, APD required two sprayers but was less toxic. Overall the technique worked well on all light coloured fabric for all soils except for the North Berwick soil and an example of the results obtained for Wemyss Bay soil on patterned cotton is presented in figure 7 .
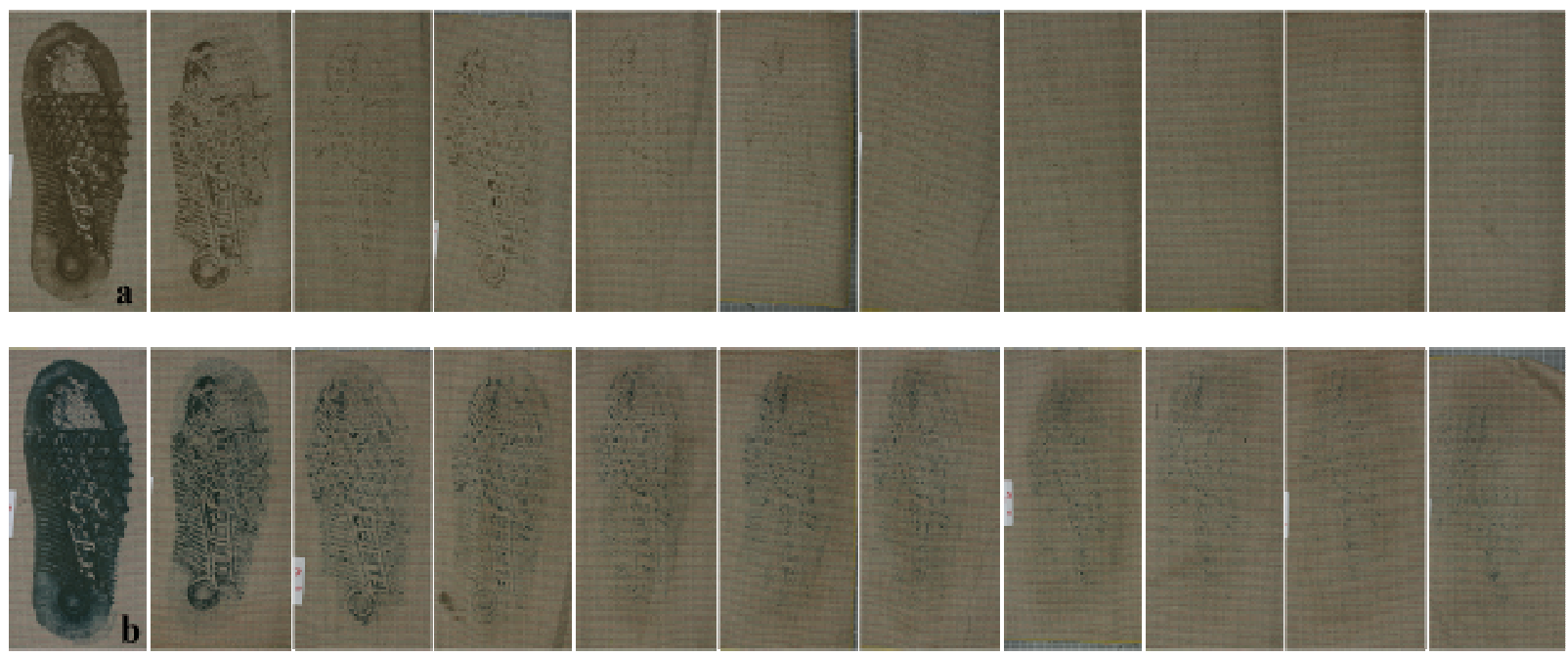

Figure 6 - Chemical enhancement of a diminishing series of footwear impressions in mud, prepared with Kilbirnie soil on pattered cotton, with potassium ferrocyanide: (a) before; and (b) after enhancement
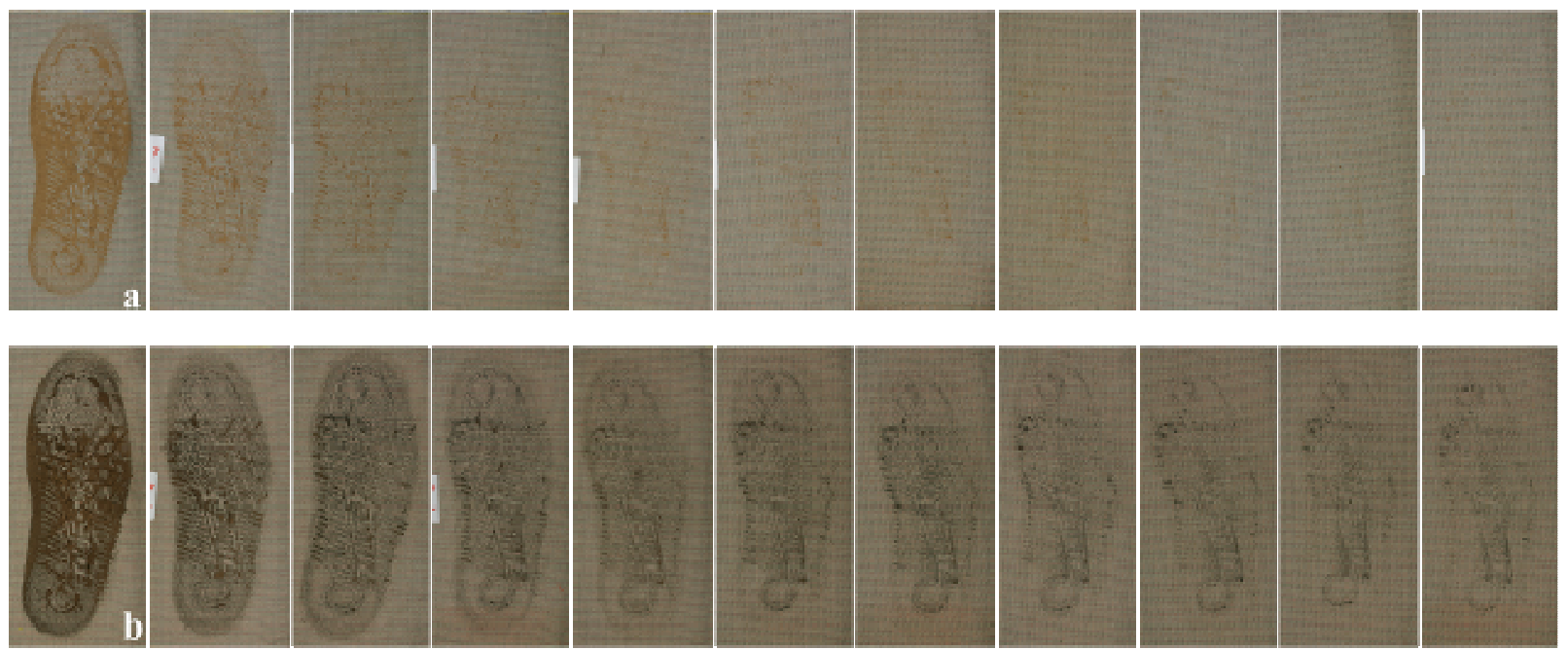

Figure 7 - Chemical enhancement of a diminishing series of footwear impressions in mud, prepared with Wemyss Bay soil on patterned cotton, with ammonium pyrrolidinedithiocarbamate: (a) before; and (b) after enhancement 


\section{2,2'-Dipyridil}

All soils appeared to be responsive to this enhancement technique producing vibrant red colours on all fabric types. The results for black fabrics, however, were only enhanced up to the third or fourth impression. The colour change took between $3-5$ minutes to develop reaching a maximum after about 24 hours. A strong colour development was observed on all light coloured fabrics up to the tenth impression in most instances. Re-application was possible without any diffusion taking place. The less toxic ethanol was used as a replacement solvent for methanol with no detriment to the enhancement obtained. In general, this technique provided the best results overall across all soils and fabrics. This contrasts the work of Someha [25] who reported potassium thiocyanate as the best enhancement technique, although it is pointed out that 2,2-dipyridil is the technique of choice in unventilated areas. Figures 8 and 9 illustrate the results obtained with 2,2'-dipyridil Wemyss Bay soil on white polyester and patterned cotton respectively, and figure 10 illustrates the level of detail obtained in the enhanced impression. Figures 11 and 12 demonstrate the effectiveness of 2,2'-dipyridil as an enhancement reagent for soil-based footwear impressions across all of the fabric and soil types under study.

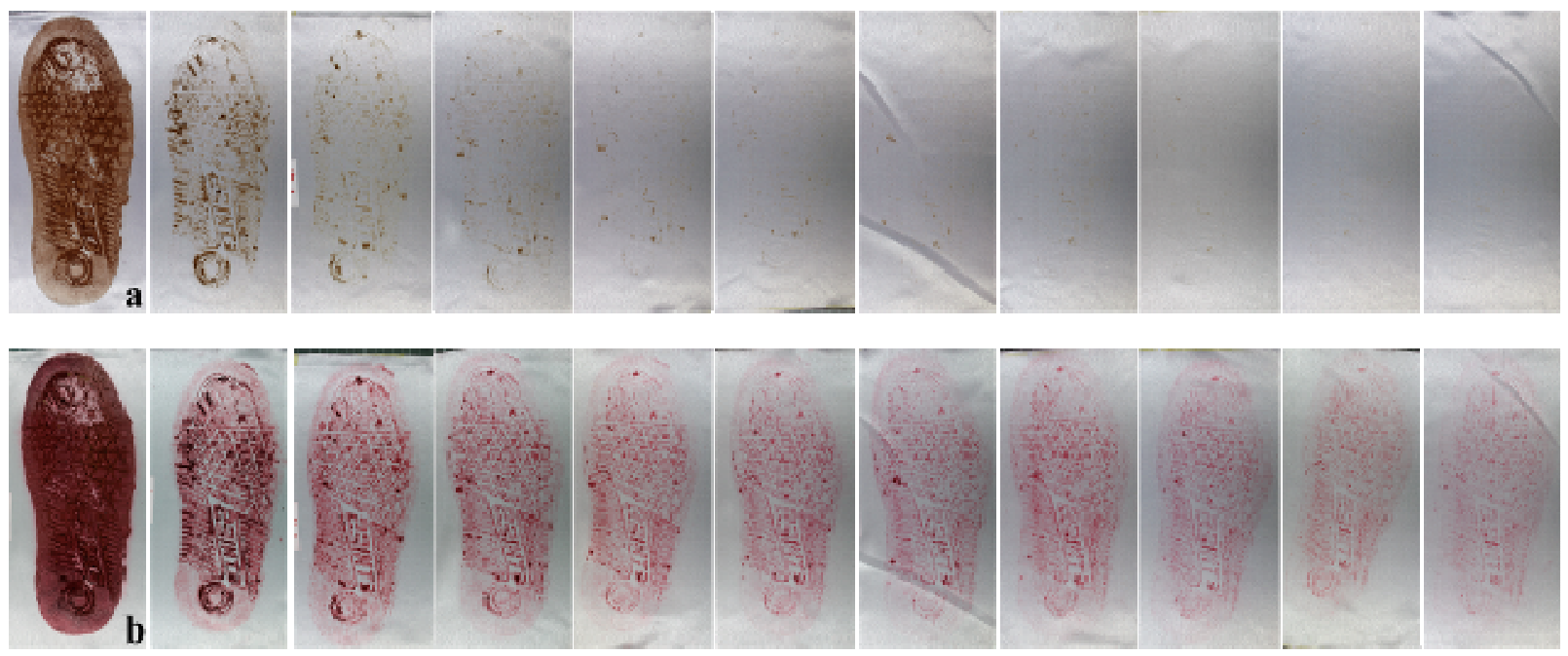

Figure 8 - Chemical enhancement of a diminishing series of footwear impressions in mud, prepared with Wemyss Bay soil on white polyester, with 2,2'-dipyridil: (a) before; and (b) after enhancement 

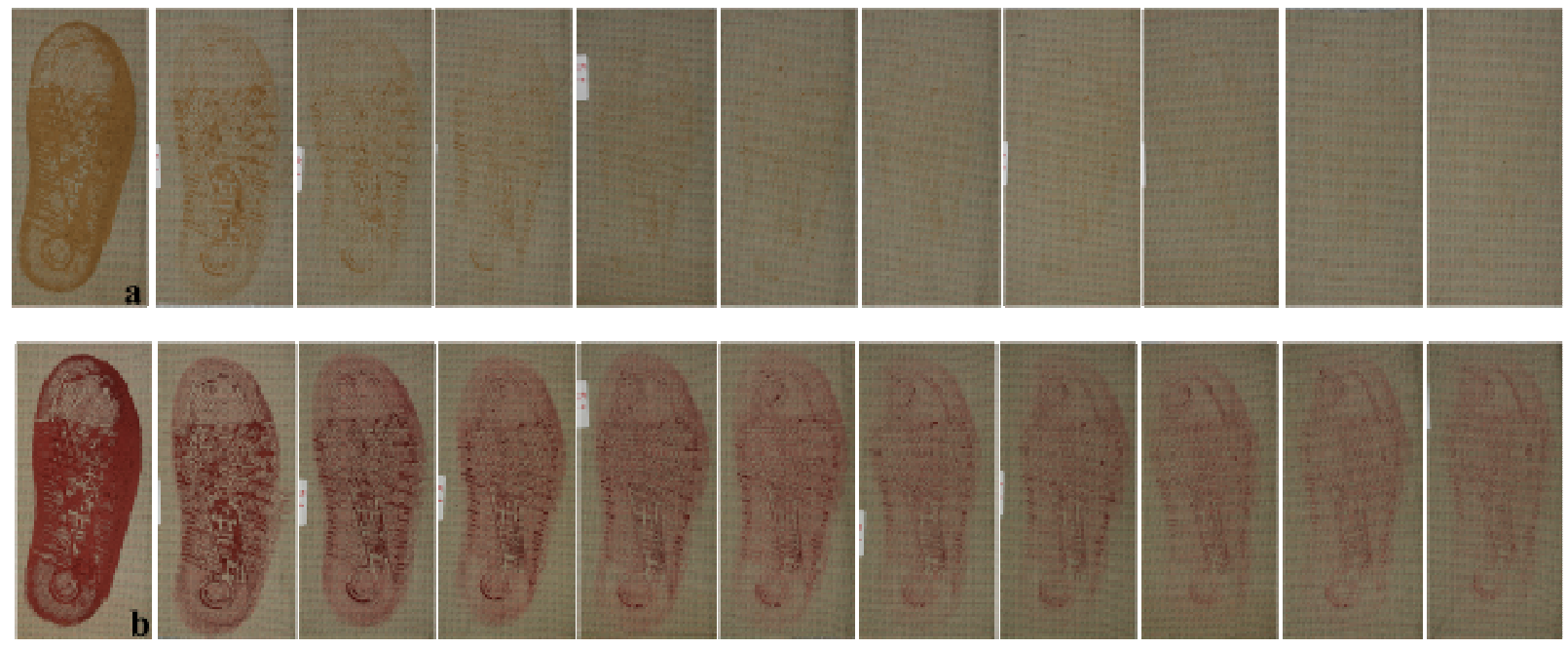

Figure 9 - Chemical enhancement of a diminishing series of footwear impressions in mud, prepared with Wemyss Bay soil on patterned cotton, with 2,2'-dipyridil: (a) before; and (b) after enhancement

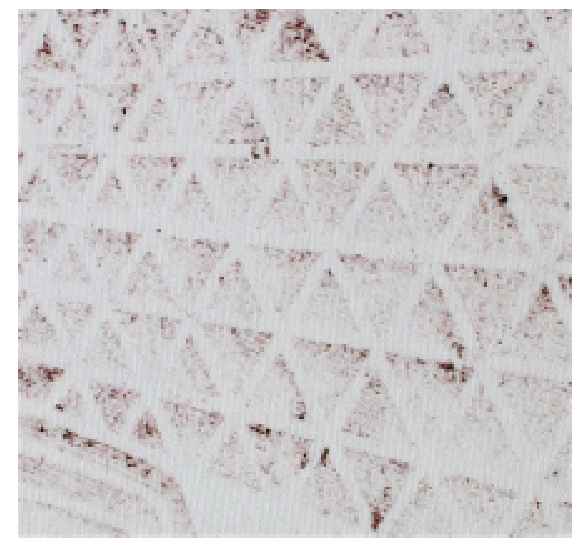

(a)

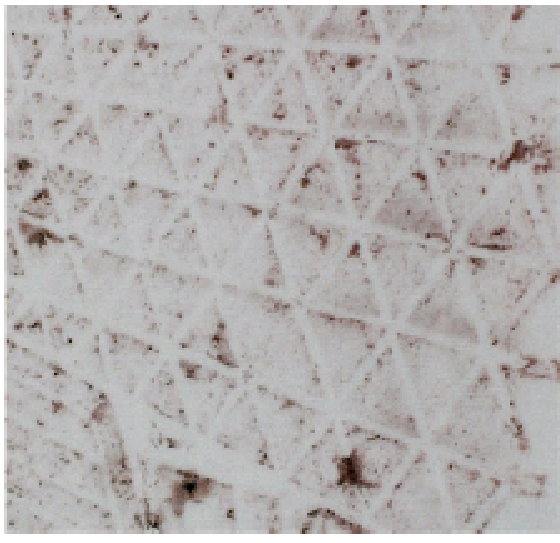

(b)

Figure 10 - Close up enhancement of a footwear impression in mud prepared with Wemyss Bay soil with 2,2'-dipyridil on: (a) white cotton; and (b) white polyester

\section{Phenanthroline Hydrosulfite (PHS)}

Weak enhancement was observed on the white fabrics with almost no enhancement observed on white nylon/lycra. Although PHS is a one-step spray process, the use of water as the main solvent resulted in some diffusion of the impression on the synthetic fabrics. The enhancement produced a faint red-orange colour, however no enhancement was achieved on the first, mostloaded impression of the diminishing series or on any of the dark or patterned fabrics. Similar to other techniques, the best enhancement was achieved on Wemyss Bay soils and is illustrated in figure 13. 

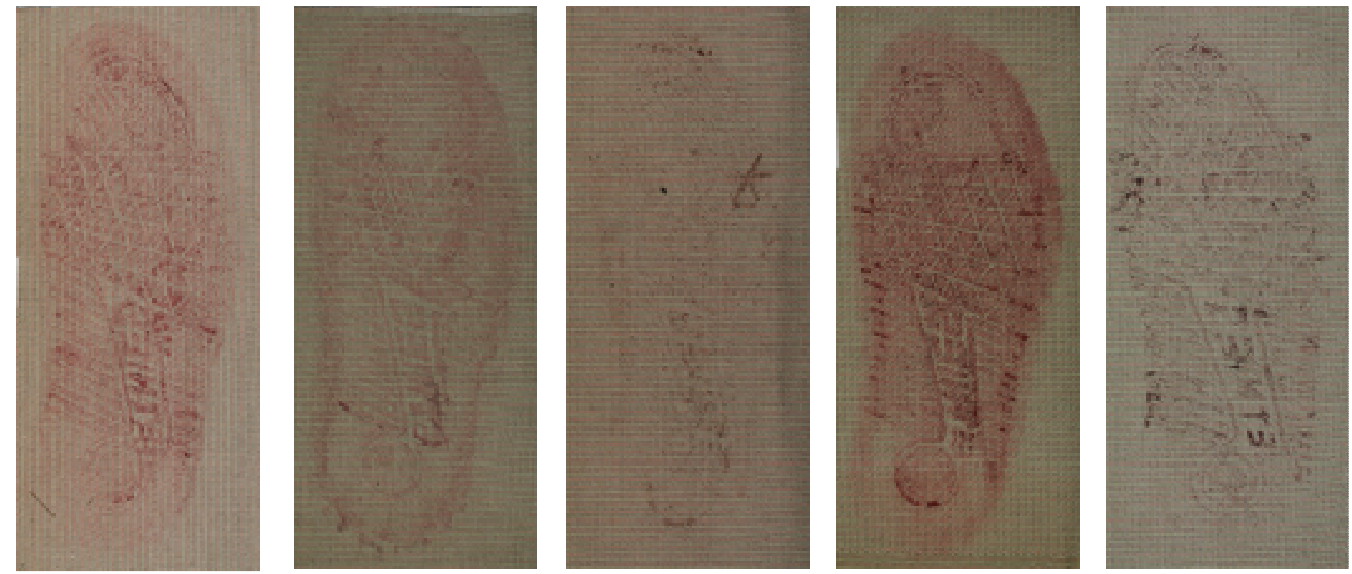

Figure 11 - Chemical enhancement of $5^{\text {th }}$ impression in a diminishing series of footwear impressions in mud, prepared with different soils on patterned cotton, with 2,2'-dipyridil (from left to right: Kilbirnie, Cornalees, North Berwick, Wemyss Bay and Road Dust Soils)

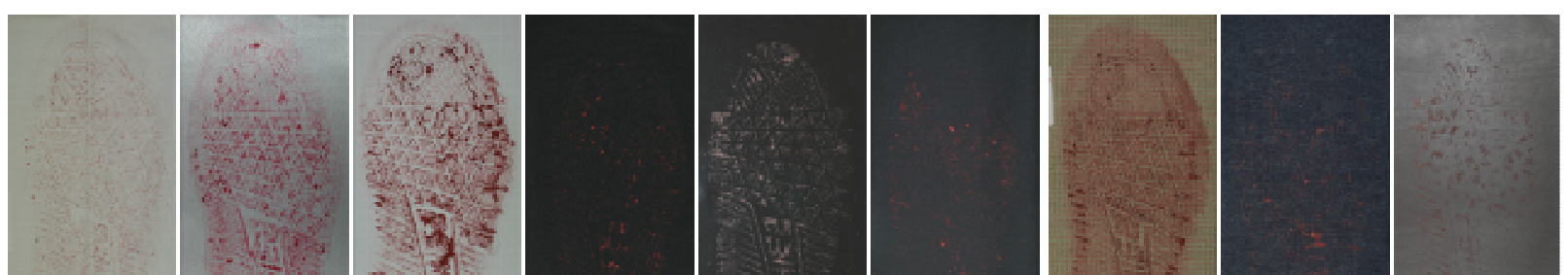




\section{Road soil sample}

Footwear impressions in mud were prepared as previously described. The techniques ammonium thiocyanate and phenanthroline hydrosulfite were omitted from the enhancement techniques for the road soil sample because of poor performance. Potassium thiocyanate, potassium ferrocyanide, ammonium pyrrolidinedithiocarbamate and 2,2'-dipyridil provided similar enhancement of footwear impressions in mud prepared with the road soil in comparison to the other soils. Figures 14 and 15 illustrate some examples of the diminishing series with a road soil sample and the enhancement achieved with the different techniques. Poor enhancement was observed on all dark fabrics whereas good contrast was obtained on all light coloured fabrics.

It was not always possible to recover the fine detail of the footwear impression due to the nature of the fabric and the contaminant as the impressions appeared to diffuse into the fabric prior to enhancement. Although, in most cases the fine detail wording on the footwear sole was not recovered, general characteristics were clearly visible as illustrated in figure 16.

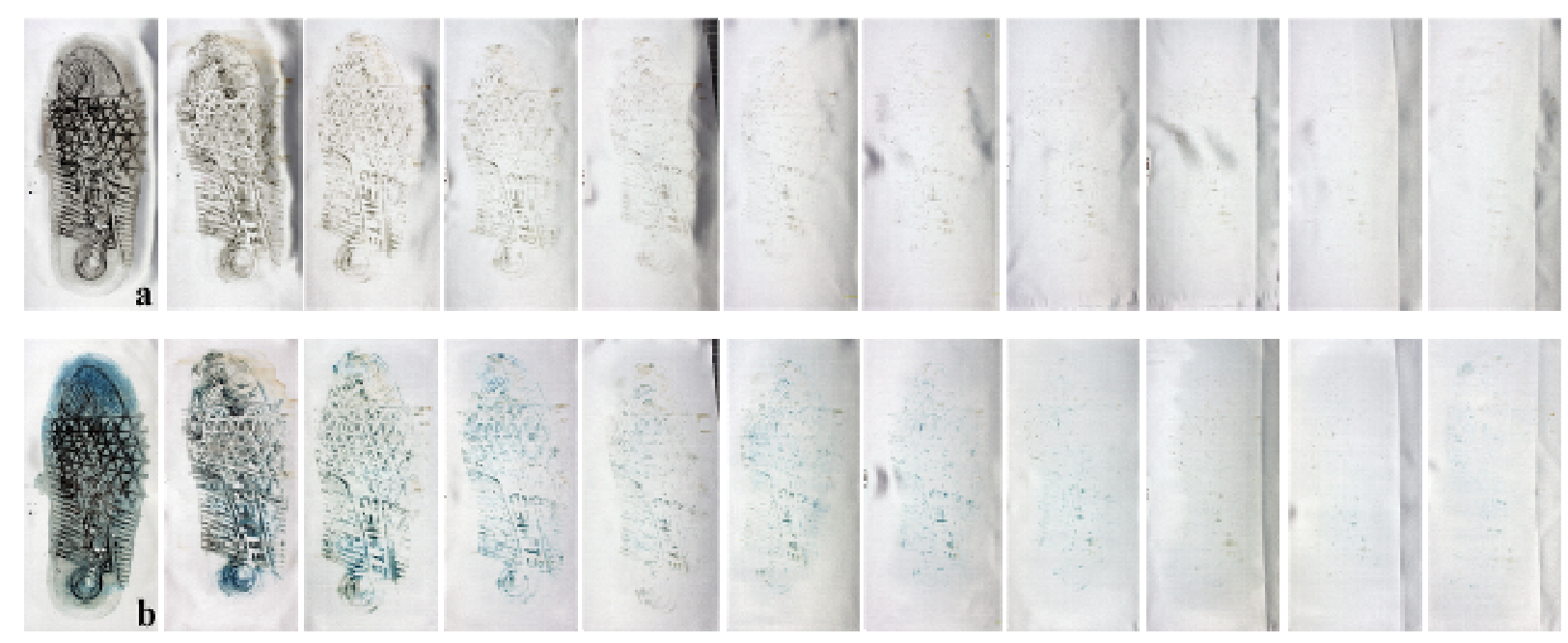

Figure 14 - Chemical enhancement of a diminishing series of footwear impressions in mud, prepared with the road soil sample on white polyester, with potassium ferrocyanide: (a) before; and (b) after enhancement 

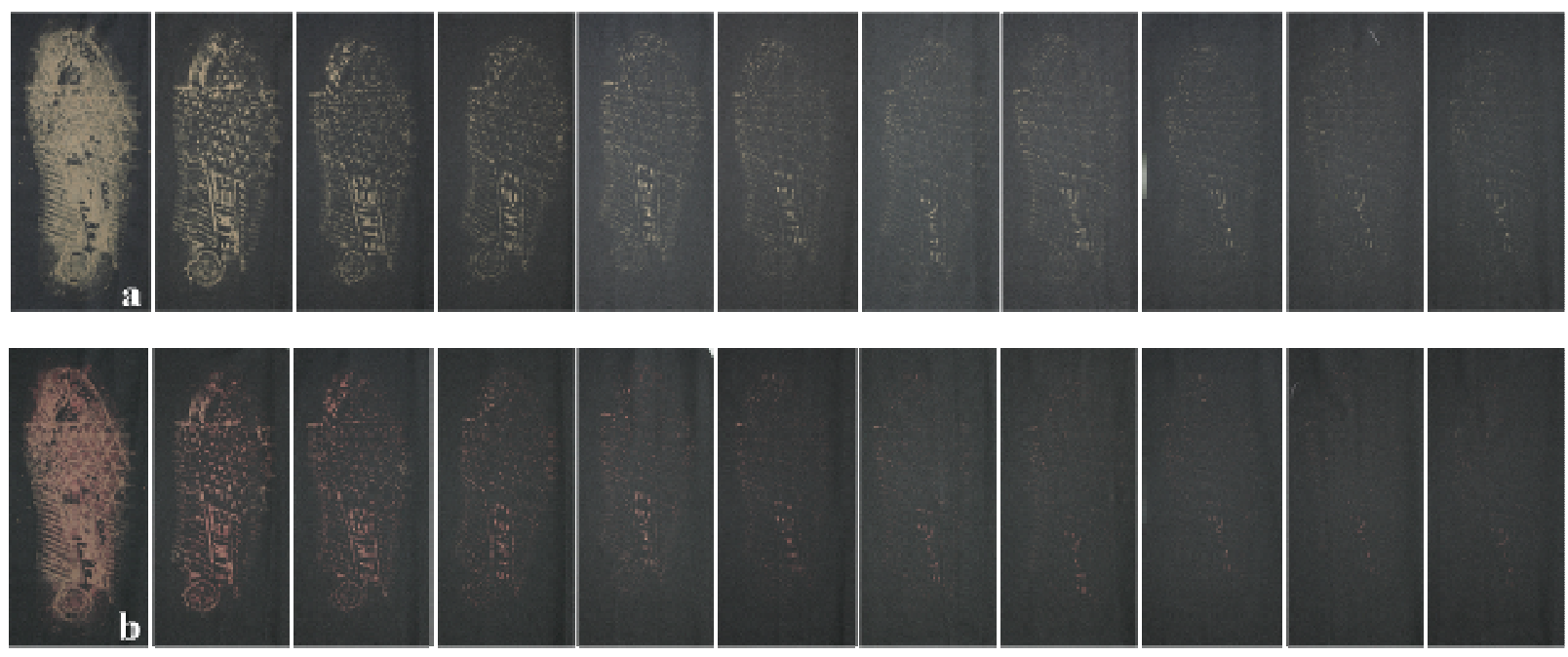

Figure 15 - Chemical enhancement of a diminishing series of footwear impressions in mud, prepared with the road soil sample on black nylon/lycra, with 2,2'-dipyridil: (a) before; and (b) after enhancement

\section{Sequencing of enhancement techniques}

Four randomised sequences of the most successful techniques were selected as shown in table 4. None of the chemical sequences tested appeared to provide better results than the other.

Sequences A and D appeared to offer enhancement throughout the whole sequence whereas the last techniques of sequences $\mathrm{B}$ and $\mathrm{C}$ appeared to not provide any added improvement. It appears from this sequential study and from the previous enhancement studies that 2,2dipyridil alone provides the best enhancement on light coloured fabrics and in some cases on darker fabrics. Potassium ferrocyanide can also be used as a substitute on darker fabrics to improve the contrast with the background. The use of more than one technique for enhancing the same footwear impression may result in diffusion leading to the obliteration of the original impression. Figure 17 shows the sequential enhancement of white polyester using sequence B. Figure $17 \mathrm{c}$ shows that the use of ammonium pyrrolidinedithiocarbamate after 2,2'-dipyridil improved the colour enhancement, however the quality enhancement appeared to diminish due to diffusion and repeated spraying. 


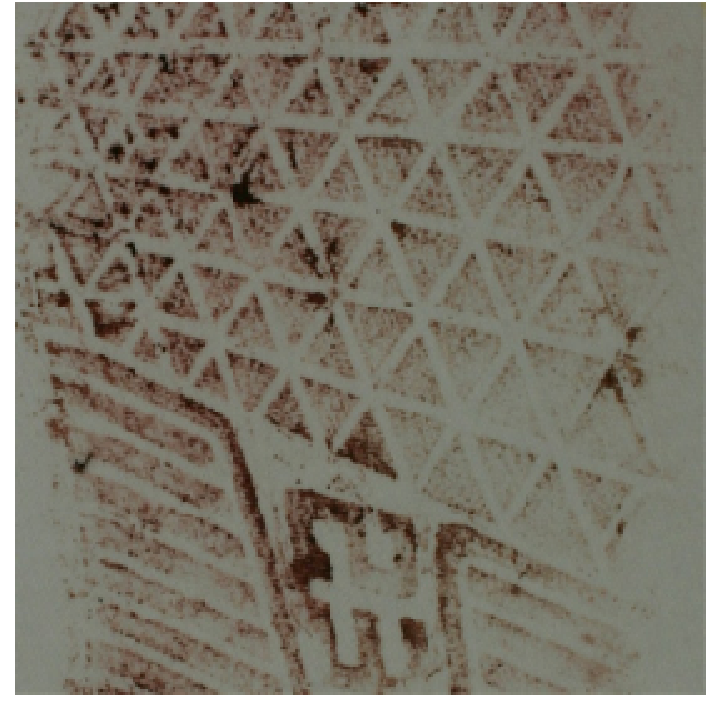

(a)

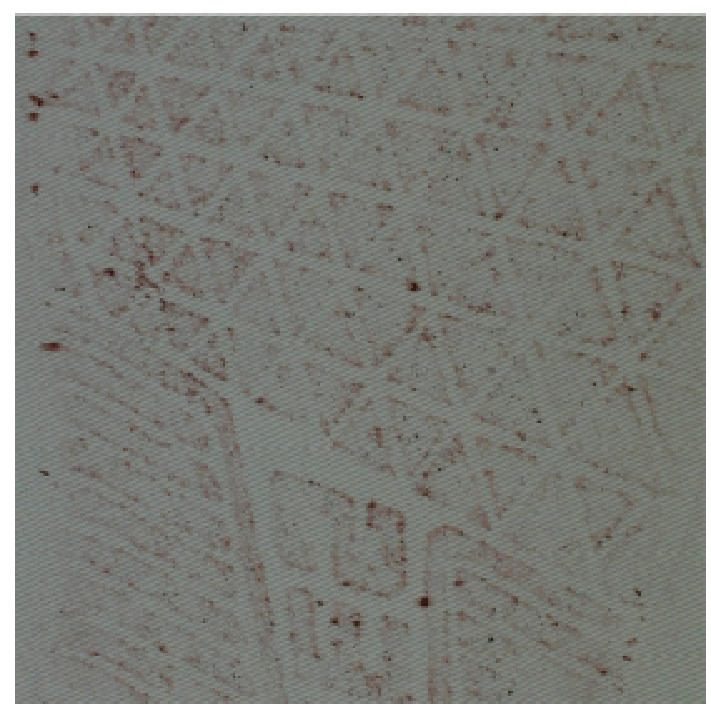

(c)

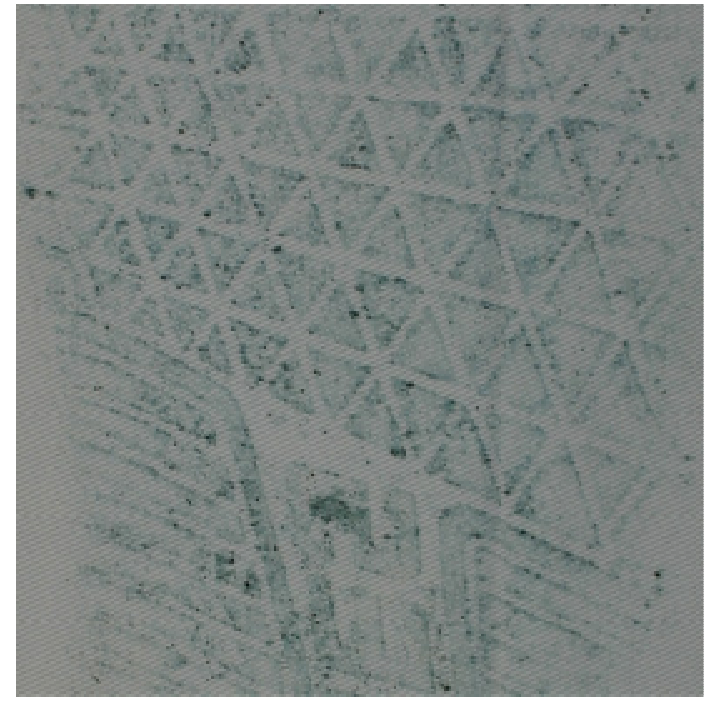

(b)

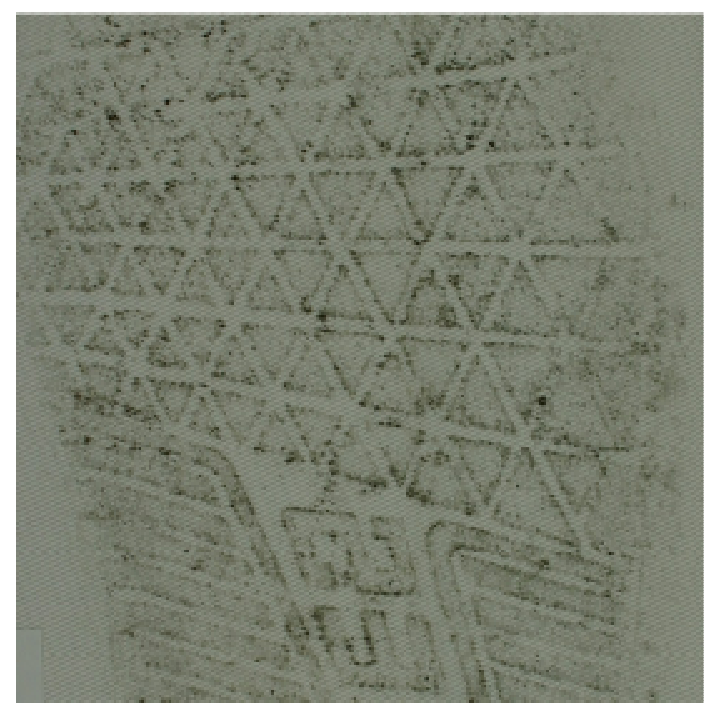

(d)

Figure 16 - Close-up detail of the enhancement of footwear impressions in mud, prepared with the road soil sample on white cotton with: (a) potassium thiocyanate; (b) potassium ferrocyanide; (c) 2,2'-dipyridil and (d) ammonium pyrrolidinedithiocarbamate 


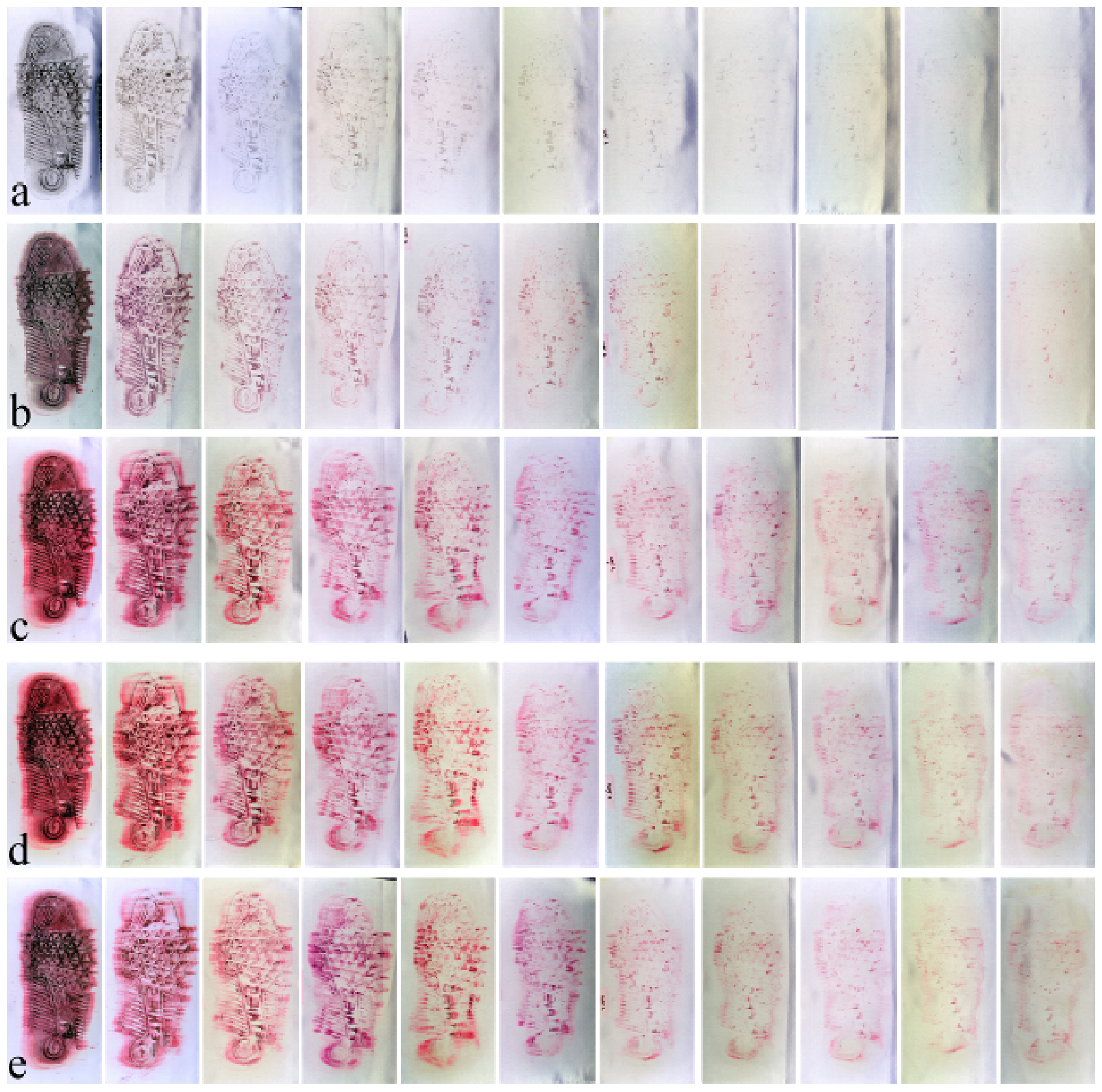

Figure 17 - Sequential enhancement (Process B) of a diminishing series of footwear impressions in mud, prepared with the road soil sample on white polyester: (a) one week old muddy footwear impressions; (b) 2,2'-dipyridil; (c) 2,2'-dipyridil + ammonium pyrrolidinedithiocarbamate; (d) 2,2'-dipyridil + ammonium pyrrolidinedithiocarbamate + potassium ferrocyanide; (e) 2,2'-dipyridil + ammonium pyrrolidinedithiocarbamate + potassium ferrocyanide + potassium thiocyanate 


\section{CONCLUSIONS}

This work has demonstrated that it is possible to enhance footwear impressions in mud on fabric and clothing. The best contrast was obtained on light fabrics. Muddy impressions on black fabrics were slightly enhanced at the beginning of the diminishing series but deteriorated as the series progressed. In general, stronger colour enhancement was obtained on synthetic fabrics (polyester and nylon/lycra), however, these fabrics were more prone to diffusion of the original footwear impression. Enhancement on denim and leatherette was poor in most cases.

2,2'-dipyridil appeared to work well on all light coloured fabrics for impressions prepared with all soils used in this study. The use of 2,2'-dipyridil for the enhancement of footwear impressions in mud can be a potential alternative to the thiocyanates. This study also demonstrated that, although sequential enhancement might improve the visualisation of footwear impressions, the use of 2,2'-dipyridil alone appeared to be sufficient to offer excellent enhancement with limited diffusion of the impression.

The enhancement of impressions in mud or dust using reagents that target common elements such as calcium, aluminium or phosphorous produced poor results even if present abundantly in soils. The effect of $\mathrm{pH}$ did not seem to play a major role in the enhancement achieved. The Wemyss Bay soil produced the best enhancement results across all fabrics for the techniques investigated. This is a mineral soil with low clay content and this may be a feature of its enhancement success. The North Berwick soil performed poorly, possibly due to its low iron levels and calcareous nature. The roadside soil sample performed better than the North Berwick soil presumably due to low iron levels in the latter. This investigation also highlights the differences that the soil type can have on the efficacy of the enhancement reagent. It is certainly worth considering the nature of the soil within a region to determine the optimum enhancement reagents which should be used for a given impression.

Further work will undertake a qualitative comparison of the best performing techniques by cutting the test impressions in mud in half and treating each half with a different technique or enhancement sequence. Additionally, the effect of slurry preparation on the enhancement techniques can also be investigated. 


\section{ACKNOWLEDGEMENTS}

The authors would like to thank CAST (HOSDB), EPSRC and the University of Strathclyde for their financial support. Special thanks to Jasmine Ross, Gordon Hudson, Malcolm Coull, Donna Macdonald, Fiona Sturgeon and Diane Smith at The James Hutton Institute, Aberdeen for their assistance in the analysis of the soils and GIS modelling. We are also grateful to James McVee at Heriot-Watt University for assistance with the SEM, Travis Coon at Gurley Precision Instruments for providing an air permeometer and to the anonymous reviewers for improving the manuscript. This work is also partially funded by the Malta Government Scholarship Scheme. 


\section{REFERENCES}

1. K.J. Farrugia, N. NicDaéid, K.A. Savage, H.L. Bandey, Chemical enhancement of footwear impressions in blood deposited on fabric - Evaluating the use of alginate casting materials followed by chemical enhancement, Science \& Justice, 50 (4) (2010) 200-204.

2. K.J. Farrugia, K.A. Savage, H.L. Bandey, N. Nic Daeid (2011) Chemical Enhancement of Footwear Impressions in Blood on Fabric - Part 1: Protein Stains, Science and Justice, 51 (3) (2011) 99-109

3. K.J. Farrugia, K.A. Savage, H.L. Bandey, T. Ciuksza, N. Nic Daéid (2011) Chemical Enhancement of Footwear Impressions in Blood on Fabric - Part 2: Peroxidase reagents, Science \& Justice, 51 (3) (2011) 110-121.

4. $\quad$ K.J. Farrugia, N. Nic Daéid, H.L. Bandey, S. Bleay (2011) Chemical Enhancement of Footwear Impressions in Urine on Fabric, Forensic Science International, In Print, doi: 10.1016/j.forsciint.2011.07.020

5. D.R. Zauner, Friction Ridge Impression in Blood on Blue Denim, Journal of Forensic Identification, 48 (6) (1998) 689-691.

6. Y. Shor, T. Tsach, A. Vinokurov, B. Glattstein, E. Landau, N. Levin, Lifting Shoeprints using Gelatin Lifters and a Hydraulic Press, Journal of Forensic Science, 48 (2) (2003) 368-372.

7. Y. Shor, T. Tsach, S. Wiesner, G. Meir, Removing Interfering Contaminants from Gelatin Lifters, Journal of Forensic Science, 50 (6) (2005) 1386-1393.

8. B. Glattstein, Y. Shor, N. Levin, A. Zeichner, pH Indicators as Chemical Reagents for the Enhancement of Footwear Marks, Journal of Forensic Science, 41 (1) (1996) 23-26.

9. Y. Shor, A. Vinokurov, B. Glattstein, The Use of an Adhesive Lifter and $\mathrm{pH}$ Indicator for the Removal and Enhancement of Shoeprints in Dust, Journal of Forensic Science, 43 (1) (1998) 182-184.

10. L.V. Keith, Footwear Impression on Fabric, Journal of Forensic Identification, 52 (6) (2002) 681-685.

11. E.D. Hamm, Back-Transfer of Footwear and Tire Tread Design on Victim Clothing, in 91st International Educational Conference 2006, International Association of Identification: Boston, Massachusetts.

12. P. Hamer, C. Price, Case Report: A Transfer from Skin to Clothing by Kicking - the Detection and Enhancement of Shoeprints, Journal of the Forensic Science Society, 33 (3) (1993) 169172.

13. S.K. David, M.T. Pailthorpe, Classification of Textile Fibres: Production, Structure, and Properties, in Forensic Examination of Fibres, Robertson, J. and M. Grieve, Editors. 1999, Taylor and Francis: London. p. 1-31.

14. S.J. Kadolph, A.L. Langford, N. Hollen, J. Saddler, Textiles, Macmillan Publishing Company, (1993)

15. J.H. Sharphouse, Leather Technician's Handbook, Leather's Producers' Association, (1983)

16. ASTM, D-737-04 Standard Test Method for Air Permeability of Textile Fabrics. 2004, ASTM International: Pennsylvania, US.

17. ASTM, D 4850-08 Standard Terminology Relating to Fabrics and Fabric Test Methods. 2008, ASTM International: Pennsylvania, US.

18. H.H. Epps, K.K. Leonas, The relationship between porosity and air permeability of woven textile fabrics, Journal of testing and evaluation, 25 (1) (1997) 108-113.

19. US Department of Agriculture, Soil Taxonomy: A Basic Sysem of Soil Classification for Making and Interpreting Soil Surveys, Soil Conservation Service Soil Survey Staff, Editor. 1975, U.S. Govt. Printing Office: Washington, DC. p. 754.

20. D.J. Brundage. Current Use of 8-hydroxyquinoline for Enhancing Footwear Impressions. in International Symposium on the Forensic Aspects of Footwear and Tire Impression Evidence, (1994) Quantico, VA: FBI Academy. 
21. D.J. Brundage. Ammonium Thiocyanate: A Successful Technique for Dusty Footwear Impressions. in International Symposium on the Forensic Aspects of Footwear and Tire Impression Evidence, (1994) Quantico, VA: FBI Academy.

22. S. Croft, N. Nic Daeid, K.A. Savage, R. Vallance, R. Ramage, The Enhancement and Recovery of Footwear Marks Contaminated in Soil: A Feasibility Study, Journal of Forensic Identification, 60 (6) (2010) 718-737.

23. B. Glattstein, Y. Shor, N. Levin, A. Zeichner. Improved Chemical Reagents for the Enhancement of Footwear Marks. in International Symposium on the Forensic Aspects of Footwear and Tire Impression Evidence, (1994) Quantico, VA: FBI.

24. E. Ross, M. Gorn, A Study of Pyridyldiphenyl-triazine as a Chemical Enhancement Technique for Soil and Dust Impressions, Journal of Forensic Identification, 60 (5) (2010) 532-546.

25. S. Someha. Chemical Techniques for the Enhancement of Footwear and Tire Impressions in Japan. in International Symposium on the Forensic Aspects of Footwear and Tire Impression Evidence, (1994) Quantico, VA: FBI Academy.

26. A.B.E. Theeuwen, S. van Barnevald, J.W. Drok, I. Keereweer, B. Lesger, J.C.M. Limborgh, W.M. Naber, R. Schrok, T. Velders, Enhancement of Muddy Footwear Impressions, Forensic Science International, 119 (1) (2001) 57-67.

27. P.R. Hesse, A Textbook of Soil Chemical Analysis, John Murray, (1971)

28. J.H. Froude, Using Ammonium Thiocyanate and Potassium Thiocyanate, Journal of Forensic Identification, 48 (6) (1998) 718-724.

29. K.R. Dunbar, R.A. Heintz, Chemistry of Transition Metal Cyanide Compounds: Modern Perspectives, in Progress in Inorganic Chemistry, Kenneth, D.K., Editor. 2007. p. 283-391.

30. D.C. Harris, Quantitative Chemical Analysis, W.H. Freeman \& Company, (2006)

31. W.J. Bodziak, Footwear Impression Evidence: Detection, Recovery and Examination, CRC Boca Raton, (2000)

32. G.L. Goldman, J.I. Thornton, A New Trace Ferrous Metal Detection Reagent, Journal of Forensic Science, 21 (3) (1970).

33. J.E. Fischer, E. Green, A Technique for the Enhancement of Shoeprints by Painting with UV Light, Identification News, 30 (3) (1980) 7-8.

34. A.B.E. Theeuwen, S. van Barneveld, J.W. Drok, I. Keereweer, J.C.M. Limborgh, W.M. Naber, T. Velders, Enhancement of Footwear Impressions In Blood, Forensic Science International, 95 (2) (1998) 133-151.

35. D.D. Garner, K.M. Cano, R.S. Peimer, T.E. Yeshion, An Evaluation of Tetramethylbenzidine as a Presumptive Test for Blood, Journal of Forensic Science, 21 (4) (1976) 816-821.

36. A.B.E. Theeuwen, S. Van Barnevald, J.W. Drok, I. Keereweer, B. Lesger, J.C.M. Limborgh, W.M. Naber, R. Schrok, M.J.M. Velders, Enhancement of Muddy Footwear Impressions, Problems of Forensic Science, 47 (2001) 405-412.

37. R.E. Gaensslen, Sourcebook in Forensic Serology, Immunology and Biochemistry, U.S. Department of Justice, (1983)

38. V.R. Holland, B.C. Saunders, F.L. Rose, A.L. Walpole, A Safer Substitute for Benzidine in the Detection of Blood, Tetrahedron, 30 (18) (1974) 3299-3302.

39. S.S. Tobe, N. Watson, N. Nic Daeid, Evaluation of six presumptive tests for blood, their specificity, sensitivity, and effect on high molecular-weight DNA, Journal of Forensic Science, 52 (1) (2007) 102-109.

40. H. Pucthler, S.N. Meloan, M.S. Terry, On the history and mechanism of alizarin and alizarin red S stains for calcium, Journal of Histochemistry and Cytochemistry, 17 (2) (1969) 110-124.

41. W. Law, Investigating the Possible Processes for the Enhancement of Shoe Marks, in Centre for Forensic Science. 2006, University of Strathclyde M.Sc.: Glasgow.

42. M.J.M. Velders. Fluorescing Mud Prints with Safranin O. in 82nd Educational Conference of the International Association for Identification, (1997) Danvers, MA, USA.

43. H.L. Bandey, Internal Report: Footwear Mark Recovery, Feasibility Study June - December 2006. 2006, HOSDB. 
44. V. Bowman, ed. Manual of Fingerprint Development Techniques. 2nd ed. 2005, Home Office Scientific Development Branch: Sandridge, UK.

45. M.J.M. Velders. Mud Prints on Paper Activated for DFO and cyanoacrylate with Black Gelatin Lifters. in 82nd Educational Conference of the International Association for Identification, (1997) Danvers, MA, USA.

46. A. Beaudoin, New Technique for Revealing Latent Fingerprints on Wet, Porous Surfaces: Oil Red O, Journal of Forensic Identification, 54 (4) (2004) 413-421.

47. A.A. Cantu, D. Burow, J.D. Wilson. On Some Properties of the Oil Red O Fingerprint Visualization Reagent. in 6th International Fingerprint Research Group (IFRG), (2007) Canberra, Australia, 25 - 30 March.

48. K. Guigui, A. Beaudoin, The use of Oil Red $O$ in Sequence with Other Methods of Fingerprinting Methods, Journal of Forensic Identification, 57 (4) (2007) 550-581.

49. N. Mack, G. Wilson, Evaluation of Oil Red O. 2007: Internal Report, Forensic Science Service (FSS) Ltd, UK Government.

50. A. Rawji, A. Beaudoin, Oil Red O Versus Physical Developer on Wet Papers: A Comparative Study, Journal of Forensic Identification, 56 (1) (2006) 33-54.

51. J. Salama, S. Aumeer-Donovan, C.J. Lennard, C. Roux. Evaluation of Oil Red O as a Fingermark Detection Reagent for use as a Replacement for or in Sequence with Physical Developer. in 6th International Fingerprint Research Group (IFRG), (2007) Canberra, Australia, 25 - 30 March.

52. M.A. Wood, T. James, ORO. The Physical Developer replacement?, Science \& Justice, 49 (4) (2009) 272-276.

53. A.D. Eaton, L.S. Clesceri, A.E. Greenberg, M.H. Franson, Standard Methods for the Examination of Water and Wastewater, American Public Health Association, (1998)

54. T. Watanabe, M. Osaki, T. Yoshihara, T. Tadano, Distribution and chemical speciation of aluminum in the Al accumulator plant, Melastoma malabathricum L., Plant and Soil, 201 (1998) 165-173.

55. R.M. Britez, T. Watanabe, S. Jansen, C.B. Reissmann, M. Osaki, The relationship between aluminium and silicon accumulation in leaves of Faramea marginata (Rubiaceae), New Phytologist, 145 (2002) 437-444.

56. N. Clarke, L.G. Danielsson, A. Sparen, Analytical methodology for determination of aluminum fractions in natural fresh waters, Pure and Applied Chemistry, 68 (8) (1996) 1597-1638.

57. N. Paine, Use of Cyanoacrylate Fuming and Related Enhancement Techniques to Develop Shoe Impressions on Various Surfaces, Journal of Forensic Identification, 48 (5) (1998) 585-601.

58. A. Mankevich. Geologic, climatic and chemical weathering considerations in the application of footwear/tire track enhancement techniques. in International Symposium on the Forensic Aspects of Footwear and Tire Impression Evidence, (1994) Quantico,VA: FBI.

59. T.M. Lovestead, T.J. Bruno, Detecting gravesoil with headspace analysis with adsorption on short porous layer open tubular (PLOT) columns, Forensic Science International, 204 (1) (2011) 156-161.

60. J. Slater, Techniques for the Enhancement of 2-Dimensional Footwear Impressions in Blood. 1995: Forensic Service Division, Australian Federal Police, Crime Scene Branch.

61. N.W. Menzies, G.L. Kerven, L.C. Bell, D.G. Edwards, Determination of total soluble aluminum in soil solution using pyrocatechol violet, lanthanum and iron to discriminate against microparticulates and organic ligands, Communications in Soil Science and Plant Analysis, 23 (17) (1992) 2525-2545.

62. E. Paterson, C.D. Campbell, M.C. Coull, C.A. Shand, Geochemical Atlas for Scottish Topsoils, The Macaulay Land Use Research Institute, (2011) 